\title{
Patient safety in marginalised groups: a narrative scoping review
}

Sudeh Cheraghi-Sohi ${ }^{1,2^{*}}$ (D), Maria Panagioti ${ }^{1}$, Gavin Daker-White ${ }^{1,2}$, Sally Giles ${ }^{1,2}$, Lisa Riste ${ }^{1}$, Sue Kirk ${ }^{1}$ Bie Nio Ong ${ }^{1,3}$, Aaron Poppleton ${ }^{1}$, Stephen Campbell ${ }^{1,2}$ and Caroline Sanders ${ }^{1,2,4,5}$

\begin{abstract}
Background: Marginalised groups ('populations outside of mainstream society') experience severe health inequities, as well as increased risk of experiencing patient safety incidents. To date however no review exists to identify, map and analyse the literature in this area in order to understand 1) which marginalised groups have been studied in terms of patient safety research, 2) what the particular patient safety issues are for such groups and 3) what contributes to or is associated with these safety issues arising.
\end{abstract}

Methods: Scoping review. Systematic searches were performed across six electronic databases in September 2019. The time frame for searches of the respective databases was from the year 2000 until present day.

Results: The searches yielded 3346 articles, and 67 articles were included. Patient safety issues were identified for fourteen different marginalised patient groups across all studies, with $69 \%(n=46)$ of the studies focused on four patient groups: ethnic minority groups, frail elderly populations, care home residents and low socio-economic status. Twelve separate patient safety issues were classified. Just over half of the studies focused on three issues represented in the patient safety literature, and in order of frequency were: medication safety, adverse outcomes and near misses. In total, 157 individual contributing or associated factors were identified and mapped to one of seven different factor types from the Framework of Contributory Factors Influencing Clinical Practice within the London Protocol. Patient safety issues were mostly multifactorial in origin including patient factors, health provider factors and health care system factors.

Conclusions: This review highlights that marginalised patient groups are vulnerable to experiencing a variety patient safety issues and points to a number of gaps. The findings indicate the need for further research to understand the intersectional nature of marginalisation and the multi-dimensional nature of patient safety issues, for groups that have been under-researched, including those with mental health problems, communication and cognitive impairments. Such understanding provides a basis for working collaboratively to co-design training, services and/or interventions designed to remove or at the very least minimise these increased risks.

Trial registration: Not applicable for a scoping review.

Keywords: Patient safety, Marginalised groups, Contributory factors, Scoping review

\footnotetext{
* Correspondence: Sudeh.cheraghi-sohi@manchester.ac.uk

${ }^{1}$ NIHR Greater Manchester Patient Safety Translational Research Centre, The University of Manchester, Williamson Building, Oxford Rd, Manchester M13 9PL, England

${ }^{2}$ Centre for Primary Care, The University of Manchester, Williamson Building,

Oxford Rd, Manchester M13 9PL, England

Full list of author information is available at the end of the article
}

(c) The Author(s). 2020 Open Access This article is distributed under the terms of the Creative Commons Attribution 4.0 International License (http://creativecommons.org/licenses/by/4.0/), which permits unrestricted use, distribution, and reproduction in any medium, provided you give appropriate credit to the original author(s) and the source, provide a link to the Creative Commons license, and indicate if changes were made. The Creative Commons Public Domain Dedication waiver (http://creativecommons.org/publicdomain/zero/1.0/) applies to the data made available in this article, unless otherwise stated. 


\section{Background}

Improving patient safety is at the forefront of healthcare policy and practice across the globe [1] but may be especially challenging for marginalised groups of patients [24]. The European Network for social inclusion and health defines marginalisation as the "position of individuals, groups or populations outside of 'mainstream society") [5]. Marginalised patients experience severe health inequities which can result in poorer health status, higher premature morbidity and increased risk for patient safety incidents in comparison to the general population [6] [2-4]. There are several reasons underlying these poor health care outcomes among marginalised patients. At the macro-level for example, marginalised people may have no voice on healthcare policy planning and/or resource allocation because they are "systemically excluded from national or international policy making forums" [5] [7]. At the meso-level, poor or non-inclusive organisational service designs can lead to gaps in service provision for marginalised patients [3]. Finally, at the micro-level, marginalised people may experience barriers to communication regarding their health care needs and treatment due to impairment or personal context (e.g. language barriers or sensory, learning or age related disability) $[8,9]$ or as a consequence of perceived [10] or actual stigma enacted (e.g. labelling of some homeless patients as 'difficult' leading to barriers in accessing care) $[3,11]$.

Although published reviews have sought to capture the nature, causes and consequences of patient safety incidents in various settings $[12,13]$, to our knowledge, none have specifically focused on marginalised populations. A scoping review is particularly suited to when the aim is to identify and map out the literature as opposed to a systematic review, which typically aims to responds to a very specific well defined research questions for a specific patient group [14]. We therefore chose the scoping review approach in order to determine the range of patient safety issues and in which types of marginalised patient groups. In order to be inclusive when mapping this potentially diverse literature, we also chose the broader definition of 'patient safety issues' [15] as opposed to a specific patient safety incident, to enable consideration of wider underlying circumstance and complexities for patients from marginalised groups as opposed to those from the general population.

This scoping review examines the range of patient safety issues for people considered to be marginalised. Our four main aims were: 1) to identify which marginalised patient groups have been studied in terms of patient safety research, 2) to understand what the particular patient safety issues are for these groups and 3) what contributes to the safety issues arising.

\section{Methods}

This scoping review was conducted in accordance with the guidance for conducting systematic scoping reviews [16].

\section{Definitions}

In the absence of an identifiable agreed definition within the literature, we chose as stated above, the European Network for social inclusion and health's definition of marginalisation, which simply states that marginalisation is the "position of individuals, groups or populations outside of "mainstream society" [5]. The definition is broad and reflects the fact that marginalisation in an umbrella term. Marginalised people however can be grouped due to them sharing common features or outcomes (e.g. reduced access to health services) as a result of their marginalisation, but may have other differing attributes (e.g. ethnicity, disability etc.) which lead or have led to their marginalisation. We do hypothesise however that marginalised groups may experience negative consequences or disparities in patient safety as a result of their marginalisation. Consequently, we also included studies utilising the terms 'seldom heard,' 'hard to read' and vulnerable groups.' The inclusion of these terms reflects the fact that they have also been used in the literature to represent the same groups designated as marginalised elsewhere in the literature. Hard-to-reach, for example, is a term cited by National Health Service (NHS) reports in the UK [17]. These reports acknowledge that certain groups are marginalised from services and therefore 'harder to reach' for health services whose goal is to provide appropriate and equitable health care for all populations. 'Seldom heard' groups have been defined as groups who may experience barriers to accessing services or are under-represented in healthcare decision making $[18,19]$. Finally, vulnerability has been defined as "susceptibility to any kind of harm whether physical, moral or spiritual, at the hands of an agent or agency" [20], a factor which "... needs to be recognised and negotiated in health care transactions." [21] . The Organisation for Economic Co-operation and Development (OECD) report into integrating Social Services for Vulnerable Groups defines 'vulnerable populations' as "people or households who live in poverty, or who are confronted with life situations that increase the likelihood of extreme forms of poverty [22]. These populations often face multiple risks and may require a range of services, from low-cost interventions such as food parcels, to more costly interventions such as housing, or mental or physical health care." Vulnerability can be identified as occurring as a result of one or more social, structural, situational or other causes. Such definitions and causes clearly have significant overlap with the 
definitions for marginalised groups and have clear applications to patient safety within a healthcare context.

\section{Patient and public involvement}

We worked with our patient-research partners in one of our departmental patient and public involvement (PPI) groups in the design of the study. Specific suggestions were made by the PPI groups and added to the protocol such as additional terms (e.g. care leaver) for the search strategy.

\section{Data sources and search strategy}

Six electronic bibliographic databases were searched from January 2000 until September 2019: MEDLINE, Embase, PsycINFO, CINAHL, ASSIA and Sociological abstracts. We selected 2000 as the start date of our searches because it coincides with when the published patient safety research began to increase in volume after the publication of the landmark report To Err is Human: Building a Safer Health System in 1999 [23]. Our search strategy (see Additional file 1) included search combinations of two key blocks of terms: Patient Safety and Marginalised groups. We used the standardised search strategy for patient safety used in previous patient safety reviews published by our research centre [24]. For the second block of terms, we used a combination of terms derived from two prior reviews on marginalisation (conducted in other topic areas) to represent the concept of marginalisation as well as terms that represent specific groups previously cited as marginalised [7, 25]. We also supplemented these terms with additional terms in order to be as comprehensive as possible. Specifically, the supplementary terms include 'hard to reach,' 'seldom heard' and 'vulnerable groups.'

\section{Eligibility criteria}

Studies were included if they met the following criteria:

\section{Inclusion criteria}

- Types of studies: empirical studies and systematic /scoping reviews. Study designs were not restricted and included both quantitative and qualitative studies including case studies;

- Types of participants: Patients who are considered to belong to a marginalised group according to the definition provided above;

- Types of outcomes: data on types of patient safety issues experienced by marginalised people and what factors lead to or were associated with these issues.

- Language: only studies published in the English Language.

\section{Exclusion criteria}

- Studies concerned with a very specific drug or medical procedure rather than broader categories of patient safety issues;

- Studies concerned with people with a single health condition (unless they also concern a marginalised group);

- Studies that are solely focused on healthcare professionals;

- Studies that are not concerned with health care related safety (e.g. safety in the home, quality of care).

\section{Study selection}

Search results were downloaded first into Endnote and then uploaded and the review process managed via the use of the review software Covidence [26]. All citations deemed relevant after title and abstract screening were retrieved for subsequent review of the full-text article. Studies were assessed for inclusion by two independent reviewers (SCS and GDW) with arbitration by a third reviewer (MP).

\section{Charting the data}

A form was developed by the authors to confirm relevance and to extract key study characteristics such as: 1) publication year, 2) publication type, 3) country, 4) economic level (as classified by the World Bank), 4) study aim, 5) population, 6) key safety outcomes and 7) contributing/associated factors related to the patient safety issues. This form was reviewed by the research team and pretested by all reviewers (SCS, GDW, AP, SG, LR and MP) before implementation. Six independent reviewers were involved in the data extraction. In particular, upon independently reviewing a batch of 20 to 30 articles, the reviewers met to resolve any conflicts and to help ensure consistency between reviewers and with the research question and purpose [27].

\section{Data synthesis}

The data were compiled in a single spreadsheet and imported into Microsoft Excel 2010 (Microsoft Corporation, Redmond, WA) for validation and coding. Studies were then coded and grouped by SCS and GDW (any disagreements were resolved via discussion) according to 1) marginalised group, 2) patient safety issues and 3) contributing or associated factors according to the 7 different factor types from the Framework of Contributory Factors Influencing Clinical Practice within the London Protocol [28] see Table 1. The London Protocol was chosen as it can be applied to all areas of healthcare reflecting the diversity in settings across included 
Table 1 The London Protocol: Framework of Contributory Factors Influencing Clinical Practice

\begin{tabular}{|c|c|}
\hline FACTOR TYPES & CONTRIBUTORY INFLUENCING FACTOR \\
\hline Patient Factors & $\begin{array}{l}\text { Condition (complexity \& seriousness) } \\
\text { Language and communication } \\
\text { Personality and social factors }\end{array}$ \\
\hline Task and Technology Factors & $\begin{array}{l}\text { Task design and clarity of structure } \\
\text { Availability and use of protocols } \\
\text { Availability and accuracy of test results } \\
\text { Decision-making aids }\end{array}$ \\
\hline Individual (staff) Factors & $\begin{array}{l}\text { Knowledge and skills } \\
\text { Competence } \\
\text { Physical and mental health }\end{array}$ \\
\hline Team Factors & $\begin{array}{l}\text { Verbal communication } \\
\text { Written communication } \\
\text { Supervision and seeking help } \\
\text { Team structure (congruence, consistency, leadership, etc) }\end{array}$ \\
\hline Work Environmental Factors & $\begin{array}{l}\text { Staffing levels and skills mix } \\
\text { Workload and shift patterns } \\
\text { Design, availability and maintenance of equipment } \\
\text { Administrative and managerial support } \\
\text { Environment } \\
\text { Physical }\end{array}$ \\
\hline $\begin{array}{l}\text { Organisational \& } \quad \text { Management } \\
\text { Factors }\end{array}$ & $\begin{array}{l}\text { Financial resources \& constraints } \\
\text { Organisational structure } \\
\text { Policy, standards and goals } \\
\text { Safety culture and priorities }\end{array}$ \\
\hline Institutional Context Factors & $\begin{array}{l}\text { Economic and regulatory context } \\
\text { National health service executive } \\
\text { Links with external organisations }\end{array}$ \\
\hline
\end{tabular}

studies. Study quality appraisals were not conducted in accordance with standard practice for scoping reviews.

\section{Results}

\section{Search and selection of studies}

The original searches yielded 3346 potentially relevant citations. After completion of deduplication and screening, 67 studies met the eligibility criteria and were included in the review. The flow of articles from identification to final inclusion is presented in Fig. 1.

\section{Description of general characteristics of included studies}

An overview of the included study characteristics is provided in Table 2. All included studies were published between 2002 and July 2019. We identified 8 reviews [29-36] and 59 empirical studies [8, 37-95]. The vast majority of these studies were conducted in high income countries $(82 \%)$, used a mixture of methods (predominantly quantitative (66\%)) and were conducted across multiple settings, with the majority (49\%) in secondary care settings. Table 3 (supplementary material) provides details of the individual included studies.

\section{Description of marginalised groups}

We identified 13 different marginalised groups within the identified literature (see Table 4). Over two thirds of studies $(69 \%)$ concerned just four marginalised groups. The largest of these (constituting over a quarter of studies $(26 \%))$ focused on ethnic minority groups [8, 32, 33, 39, $43,46,56,59,61-63,66,74,82,84,93,94]$, those residing in care homes (18\%) [29, 32, 36, 54, 65, 77-79, 81, 85, 86, 88 ], followed by frail elderly populations (15\%) [34, 37, 38, $51-53,68,73,75,83,91,92,95]$, and individuals of low socio-economic status (10\%) [40, 41, 60, 69, 72, 87, 90].

\section{Description of patient safety issues}

We identified 12 separate patient safety issues (see Table 4) within the included studies. Over half of the studies concerned three major patient safety topics. The largest of these, (constituting just over a quarter of the studies (28\%)) focused on varying aspects of medication safety [29, 32, 34, $43,44,49,50,55,64,65,69,77-79,85,86,88$, 92], followed by adverse outcomes (e.g. increased risk of hospital readmission) (22\% of all studies) [36, 51-54, 57, 68, 72-75, $81,83,84,93$ ] and near miss in maternal care (10\%) [40, $48,62,71,76,87,90,94]$. 


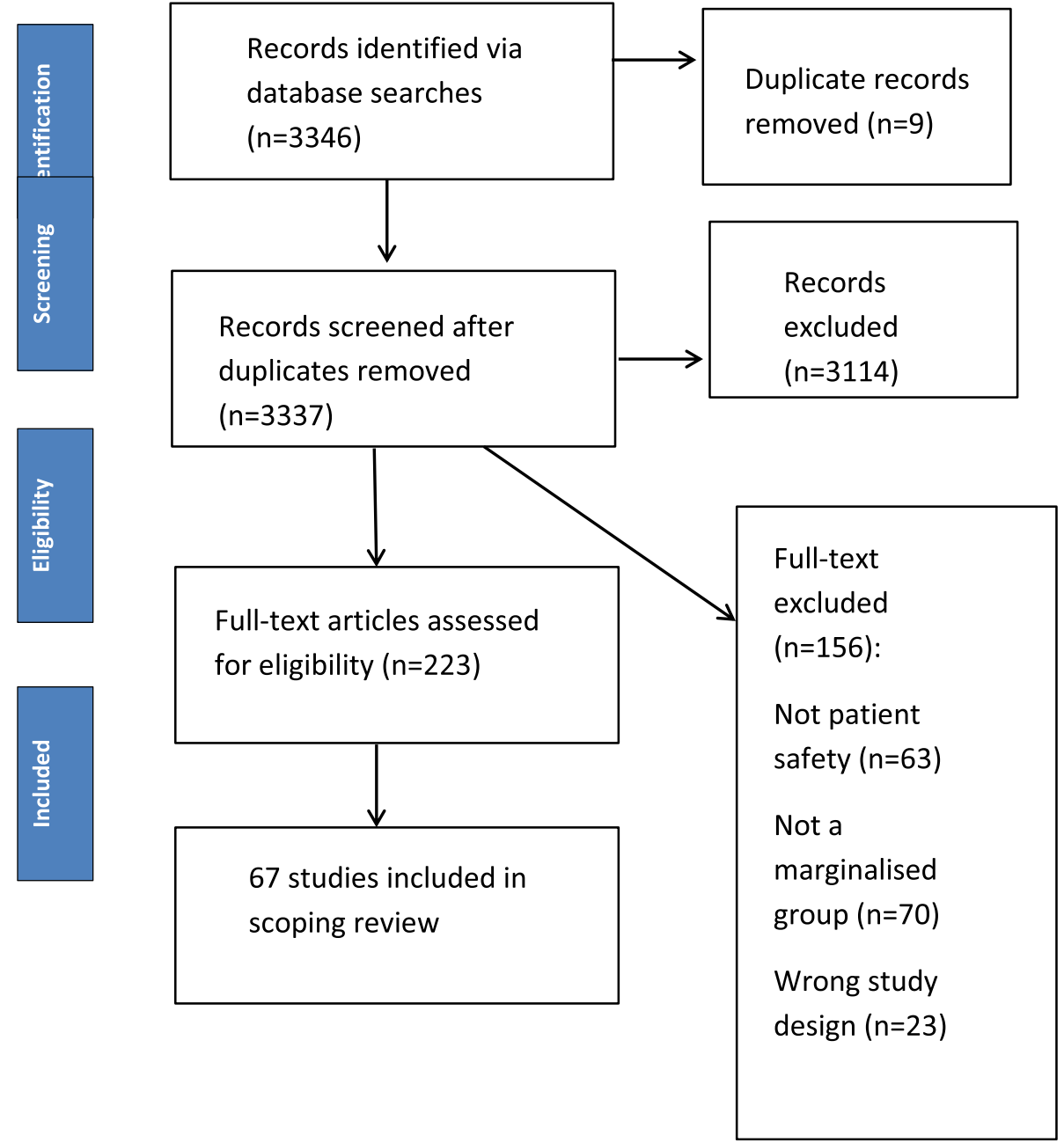

Fig. 1 PRISMA flow diagram

\section{Overview of marginalised groups and patient safety issues}

Figure 2 represents the distribution of patient safety issues and marginalised groups identified across included studies. Most patient safety issues (9/12) were repeatedly reported across more than one study except for four unique issues (culturally unsafe healthcare ${ }^{1}$ [46], diagnostic delay [60], inpatient safety [47] and medical error [38]). Similarly, most marginalised groups (9/13) were studied in more than one study. The largest proportion of studies were in two areas, 1) medication safety issues in care home residents $[29,54,65,77-79,81,85,86,88$, 92] and 2) studies of adverse outcomes in frail elderly populations [51-53, 68, 73, 75, 83].

\footnotetext{
${ }^{1}$ This study defined culturally unsafe practice as any actions that diminish, demean, or disempower the cultural identity and well-being of an individual and applied this concept to health care.
}

\section{Description of contributory/associated factors}

In total, 157 factors, ${ }^{2}$ mapped to one of 7 different factor types (from the London Protocol), contributed to or were associated with patient safety issues (see Table 5). In the vast majority of studies (52 or $78 \%$ ) the identified feature(s) of marginalisation (e.g. a patient factor such as frailty) led to patients in that group experiencing negative implications for their patient safety thereby leading authors to conclude that the characteristic itself was a contributing/associated factor to the patient safety issue of interest. Four studies reported no discernible/neutral effect $[36,59,84,92]$, two indicated a positive effect on patient safety $[55,88]$ and one mixed effects as two outcomes were measured and had different directions [93].

${ }^{2}$ Within studies, multiple factors were counted individually e.g. if ethnicity and the person's condition where both identified, then these would be counted separately within the patient domain. Additionally, where studies indicated multiple instances of the same individual factor, these were also counted separately. 
Table 2 General Characteristics of Included Studies

\begin{tabular}{|c|c|c|}
\hline General Characteristics of included studies & $\begin{array}{l}\text { Number } \\
(n=67)\end{array}$ & Percentage (\%) \\
\hline \multicolumn{3}{|l|}{ Publication Year } \\
\hline$<2005$ & 3 & 5 \\
\hline 2005-2009 & 10 & 15 \\
\hline 2010-2014 & 26 & 38 \\
\hline$\geq 2015$ & 28 & 42 \\
\hline \multicolumn{3}{|l|}{ Publication type } \\
\hline Empirical studies & 59 & 89 \\
\hline Reviews & 8 & 11 \\
\hline \multicolumn{3}{|l|}{ Economic Level of Study Country } \\
\hline High & 55 & 82 \\
\hline Upper-Middle & 6 & 10 \\
\hline Lower-Middle & 3 & 5 \\
\hline Low & 1 & 2 \\
\hline Unclear $^{\mathrm{a}}$ & 2 & 3 \\
\hline \multicolumn{3}{|l|}{ Study Setting } \\
\hline Primary & 3 & 5 \\
\hline Secondary & 32 & 49 \\
\hline Tertiary & 2 & 3 \\
\hline Care home & 12 & 16 \\
\hline Population & 4 & 6 \\
\hline Community & 3 & 3 \\
\hline Multiple & 8 & 11 \\
\hline Not specified/ Unclear & 3 & 5 \\
\hline \multicolumn{3}{|l|}{ Study Methods } \\
\hline Qualitative & 13 & 16 \\
\hline Quantitative & 43 & 67 \\
\hline Mixed (Qualitative and Quantitative) & 3 & 5 \\
\hline Review & 8 & 11 \\
\hline
\end{tabular}

${ }^{\mathrm{a}}$ Both studies were reviews which did not extract data to allow the identification of this characteristic

In 7 studies, no factors were identified [31, 34, 50, 58, $65,78,81$ ] and in two, it was unclear [44]. Most studies reporting factors, discussed multiple individual factors (range $=1-7$, average $=2.3$ ) across multiple domains (range $=1-4$, average $=2.0$ ). The single largest domain concerned patient factors with 95 counts followed by individual staff factors $(n=27)$ and institutional context $(n=16)$. A brief summary of examples in each factor type is presented beneath and ordered by frequency from highest to lowest count.

Patient factors $(n=95)$

This was the largest factor type, with $61 \%$ of all individual factors being identified as belonging to this category. We classified any contributing or associated factors that were either intrinsic to the patient or as a result of their social/economic/cultural characteristics as belonging to this factor type. There was wide variation in the types of examples, but a patients' race/ethnicity, their condition (mental and/or physical e.g. frailty, disability), issues in communication capabilities (language, disability or literacy) and help-seeking behaviour (e.g. route of admission, cultural beliefs, how they perceived themselves to be treated by clinical staff) were the largest sub-categories within this factor type.

Individual (staff) factors $(\boldsymbol{n}=27)$

Communication skills (e.g. perceived behaviour/manner towards patients) issues as well as knowledge/cognition based errors (e.g. errors in prescribing) were most commonly identified amongst coded examples. A lack of policy adherence/enactment by clinicians was also identified. However, an example of how this factor can positively impact on patient safety was seen in one study which hypothesised the outcome to be due to recognition of patient vulnerability (arising from their intellectual disability) resulting in more considered/careful behaviour by clinicians.

\section{Institutional context factors $(n=16)$}

Access to care was the largest example of this factor, particularly access being moderated by the requirement for patients to make (co-)payments in order to access care. Policies in terms of a lack of, or lack of enactment as well as issues in transitions of care (e.g. lack of consideration and responsiveness to patient factors) were also identified as leading to patient safety issues occurring.

\section{Organisational \& Management Factors $(n=8)$}

Organisational policies availability and their variation in implementation was the primary example of this factor. Organisational size, specialisation i.e. staff and patient type within the organisation and responsiveness were also identified as impacting on patient safety.

\section{Work environmental factors $(n=7)$}

Staff workload, shortages and time pressures led to patients' perceptions of staff 'busyness' and in one case, perceived patient neglect formed the coded examples in this factor type.

\section{Task and technology factors $(n=2)$}

Only two occurrences of this factor were identified (the availability of communication tools and personally held written health information) and both arose from the same study concerning patients with communication impairment/disability. 


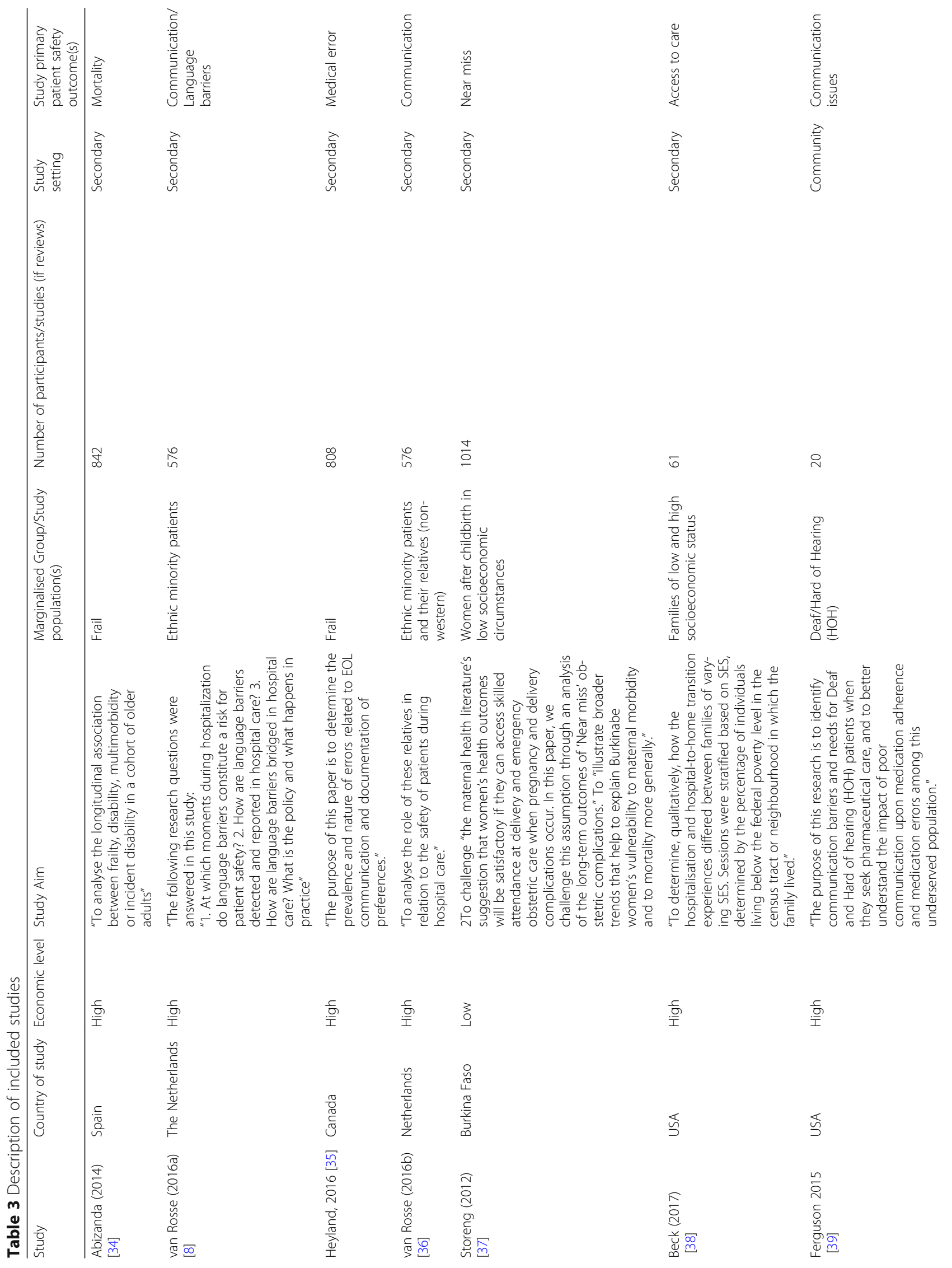




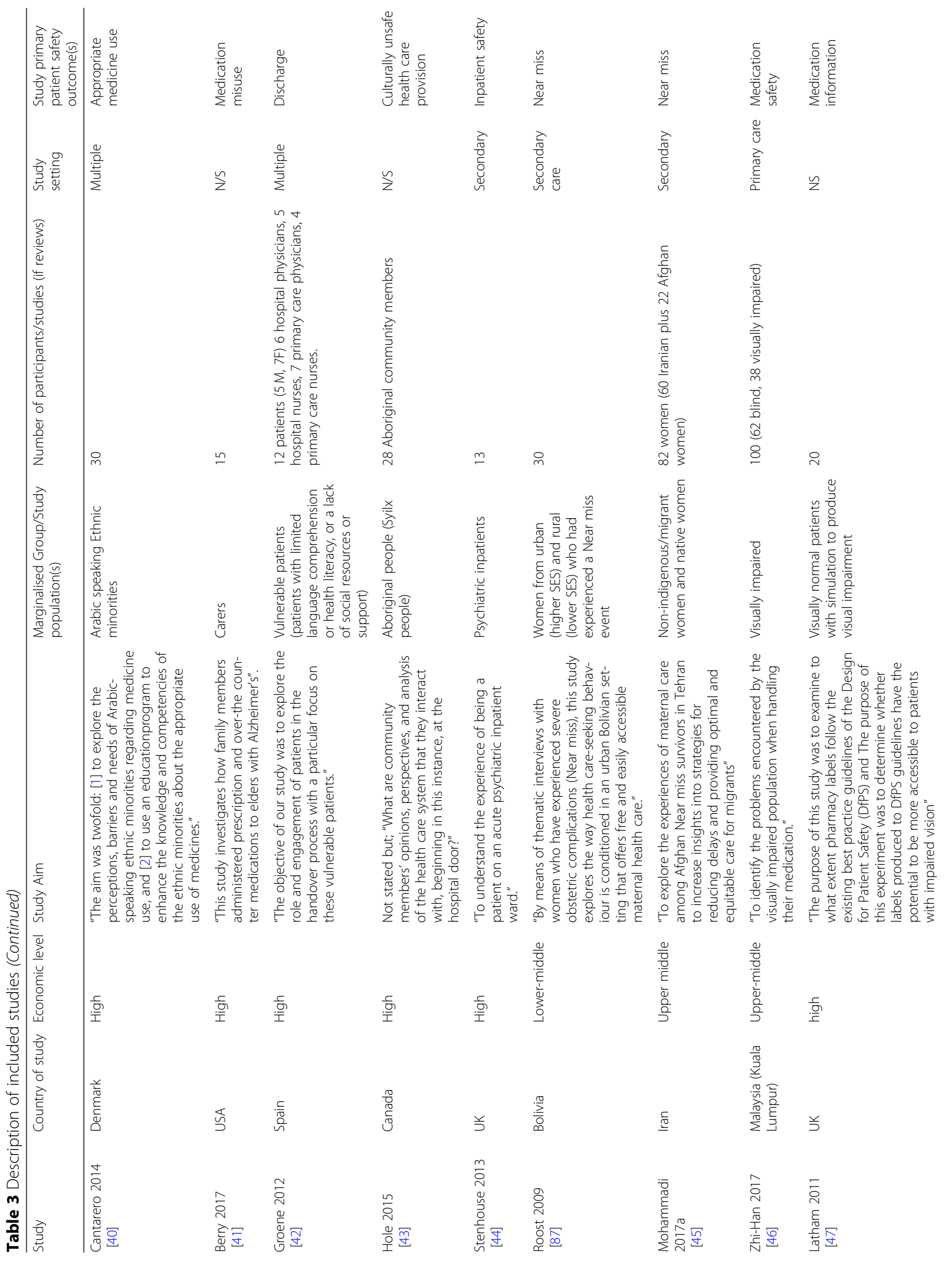




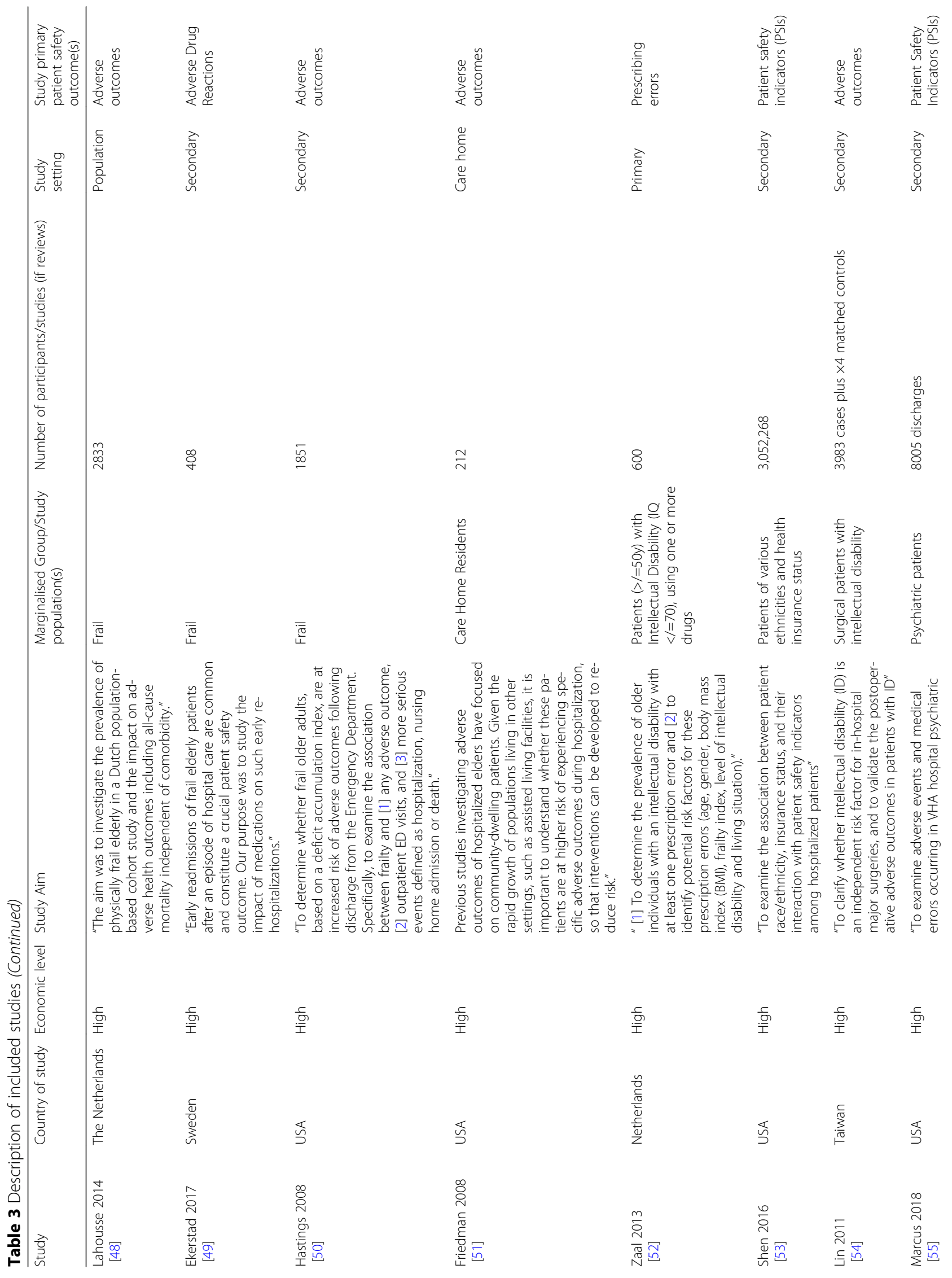




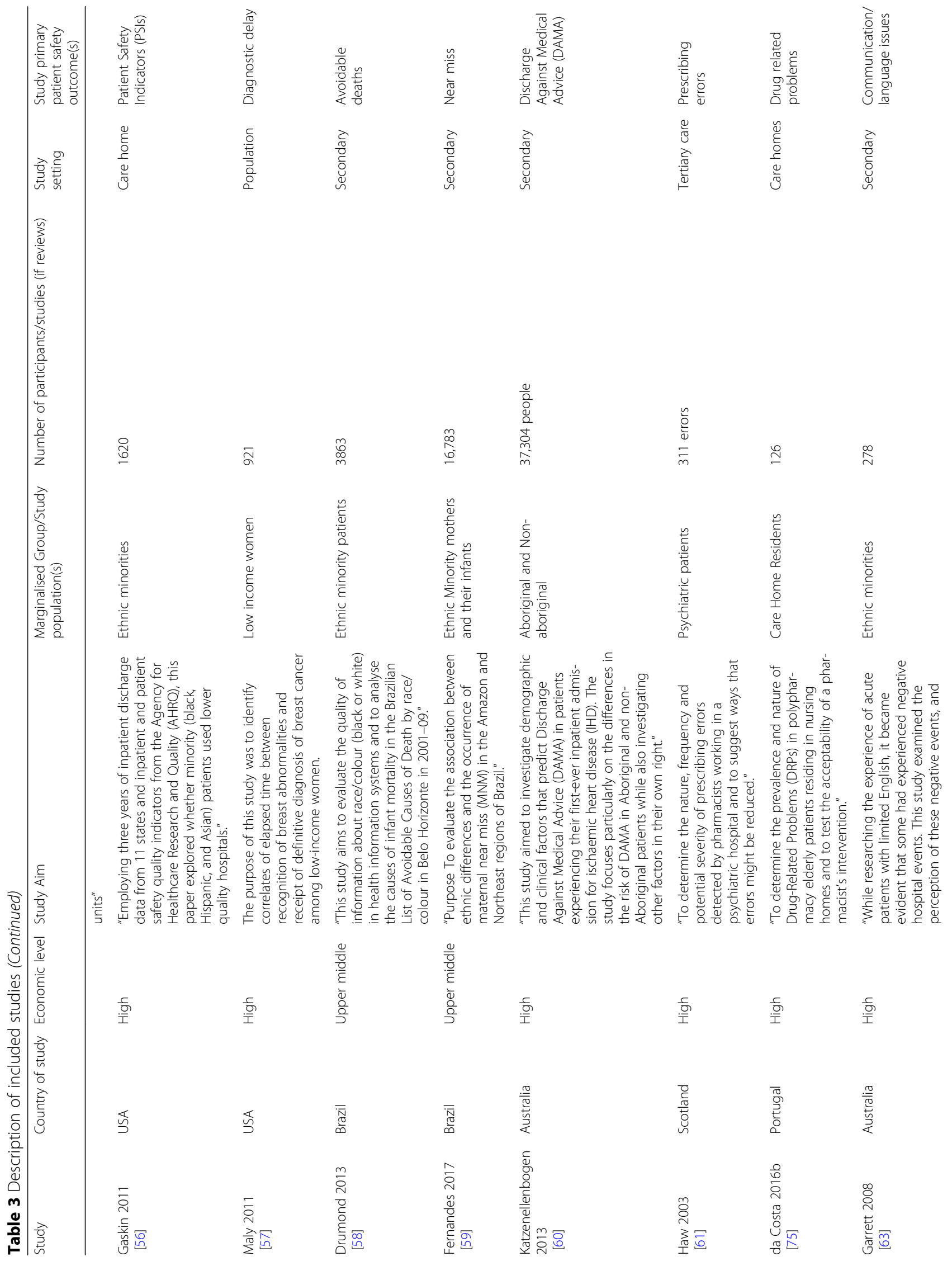




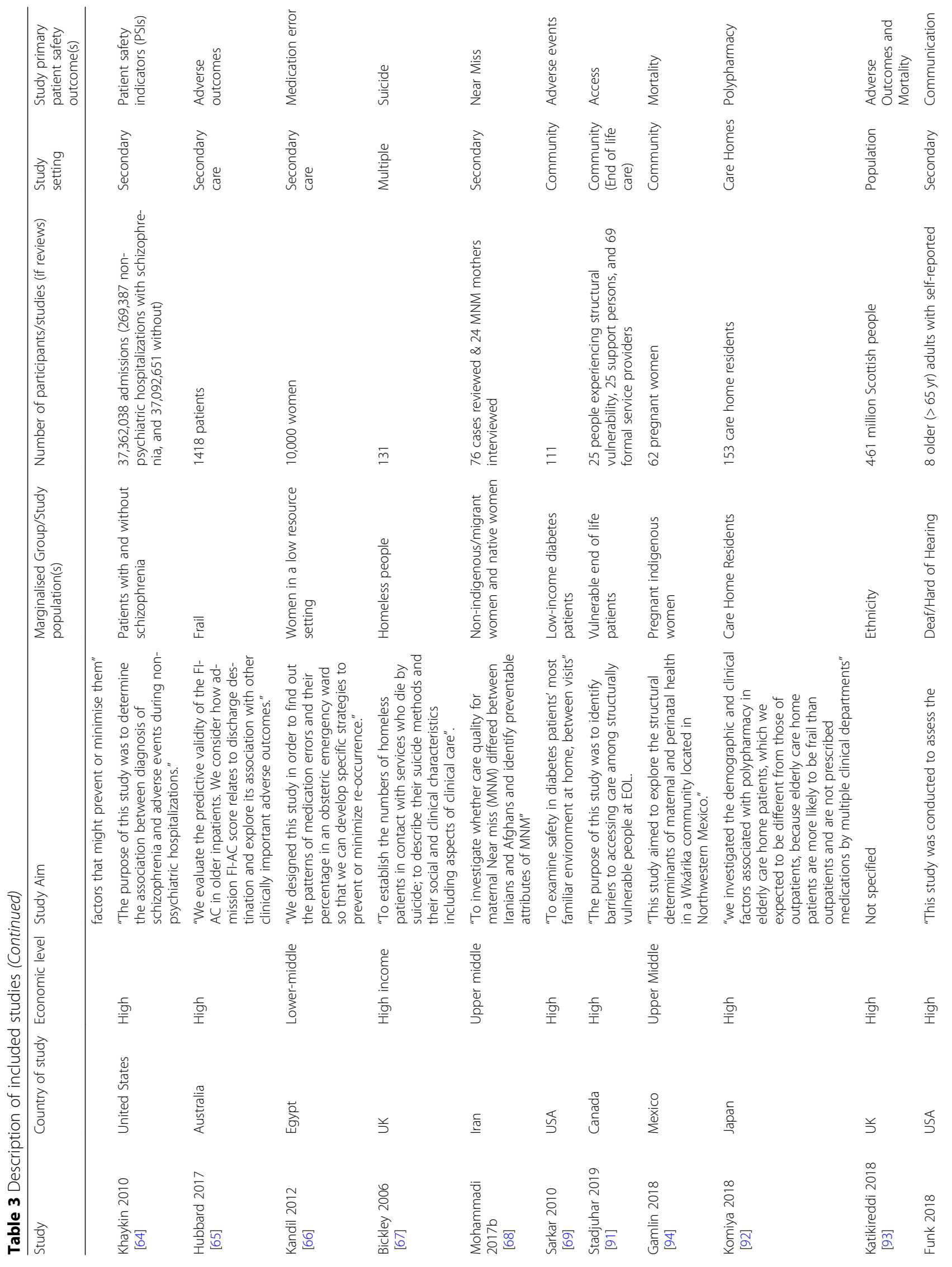




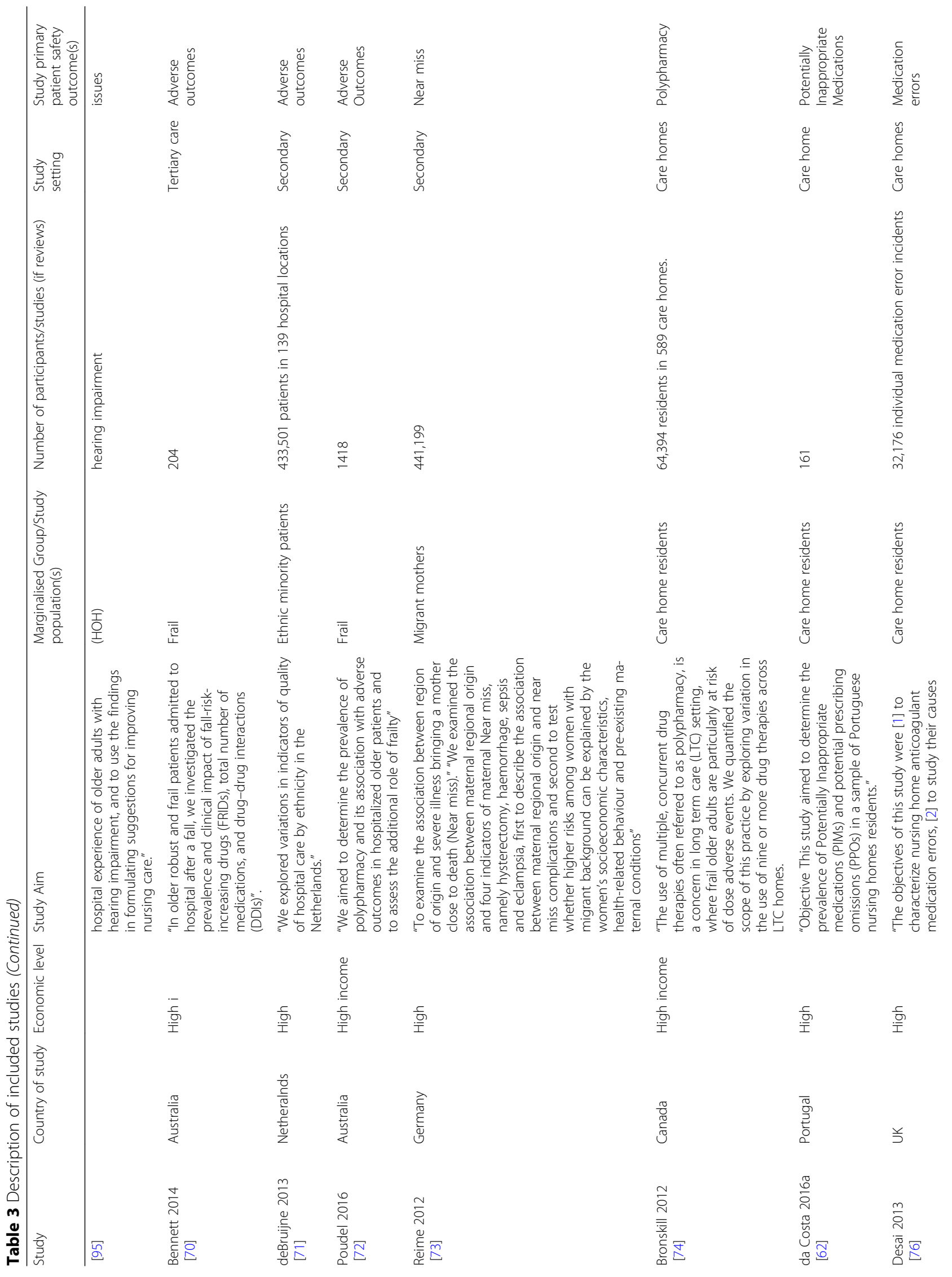




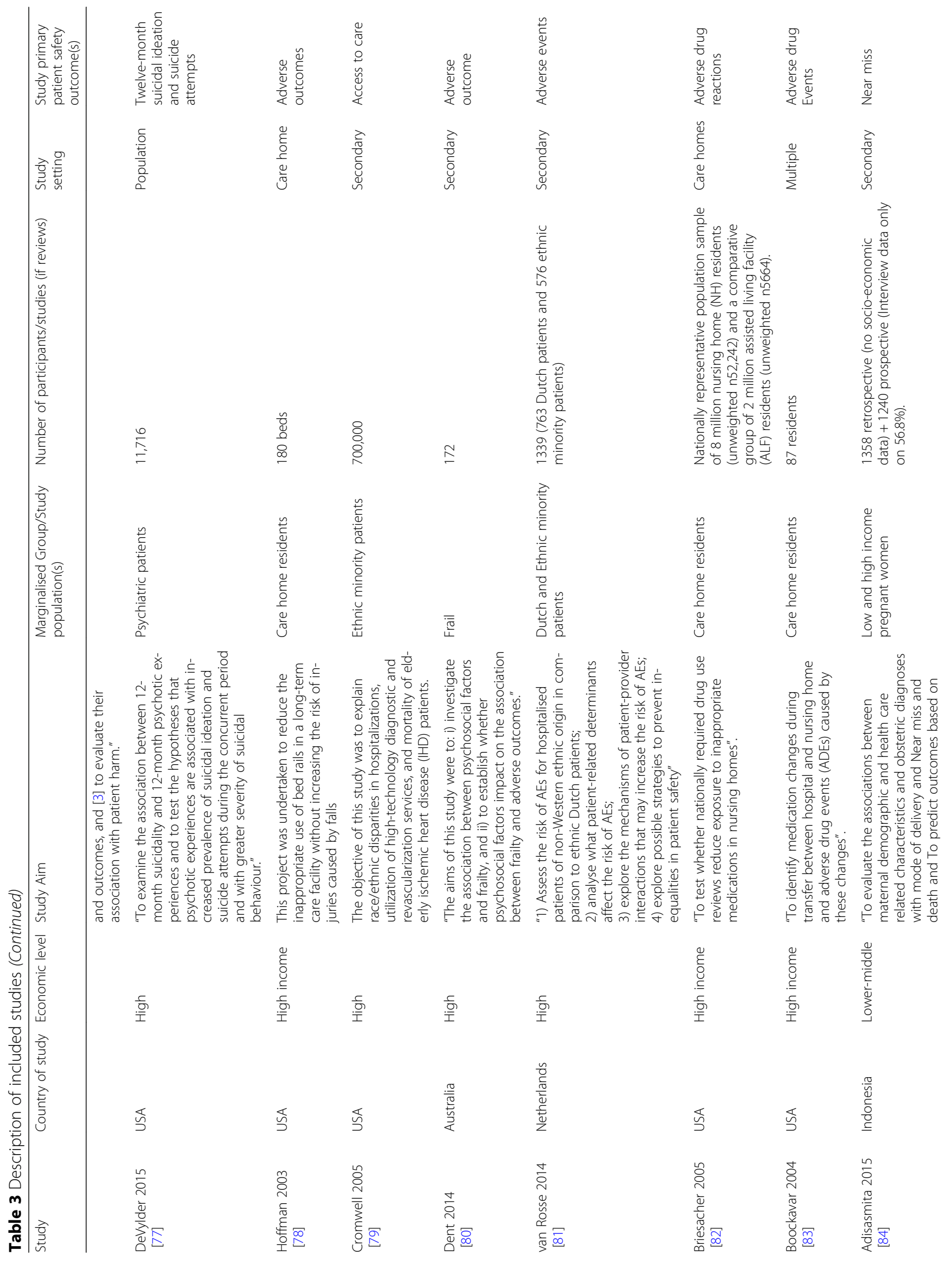




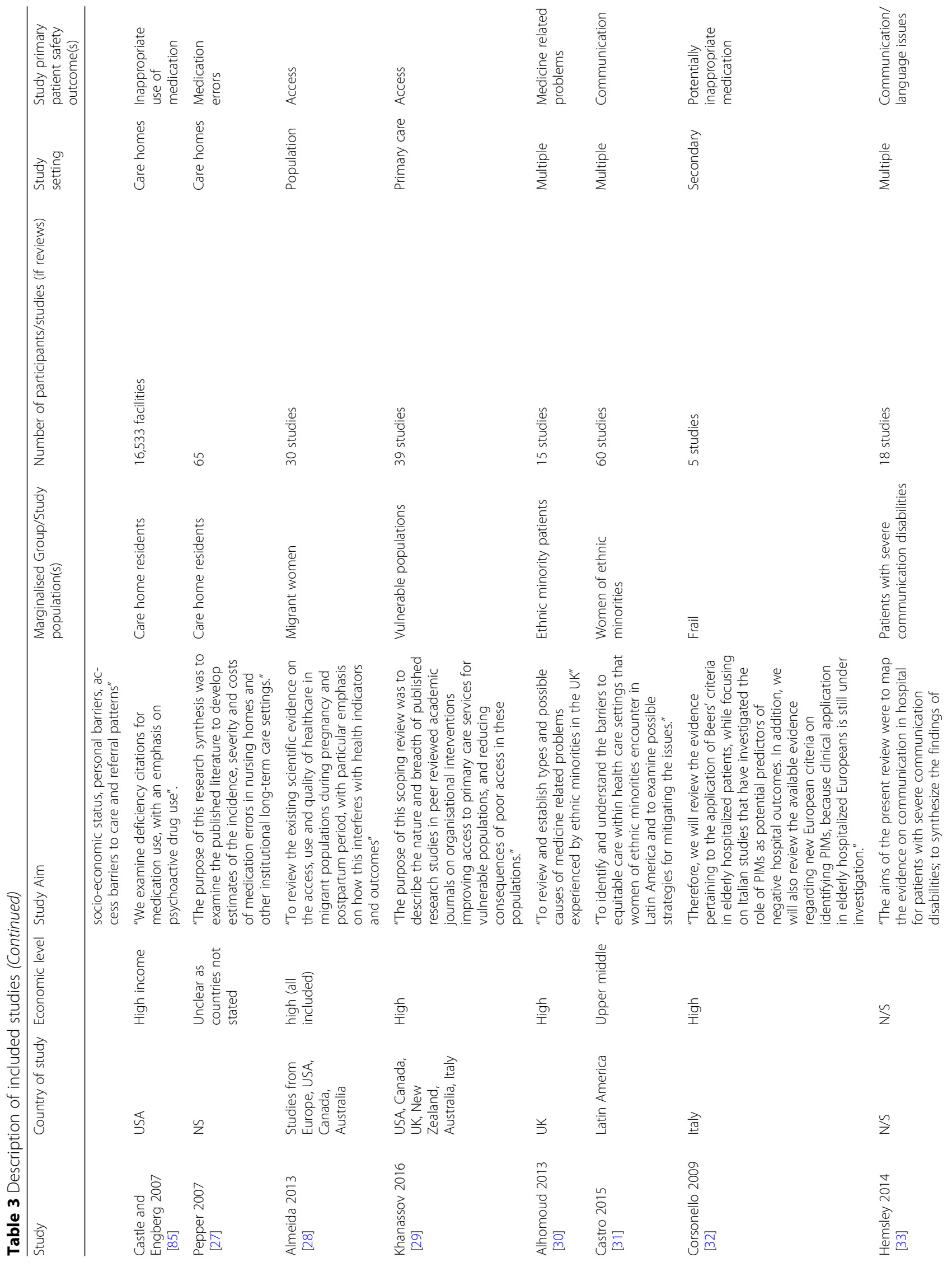




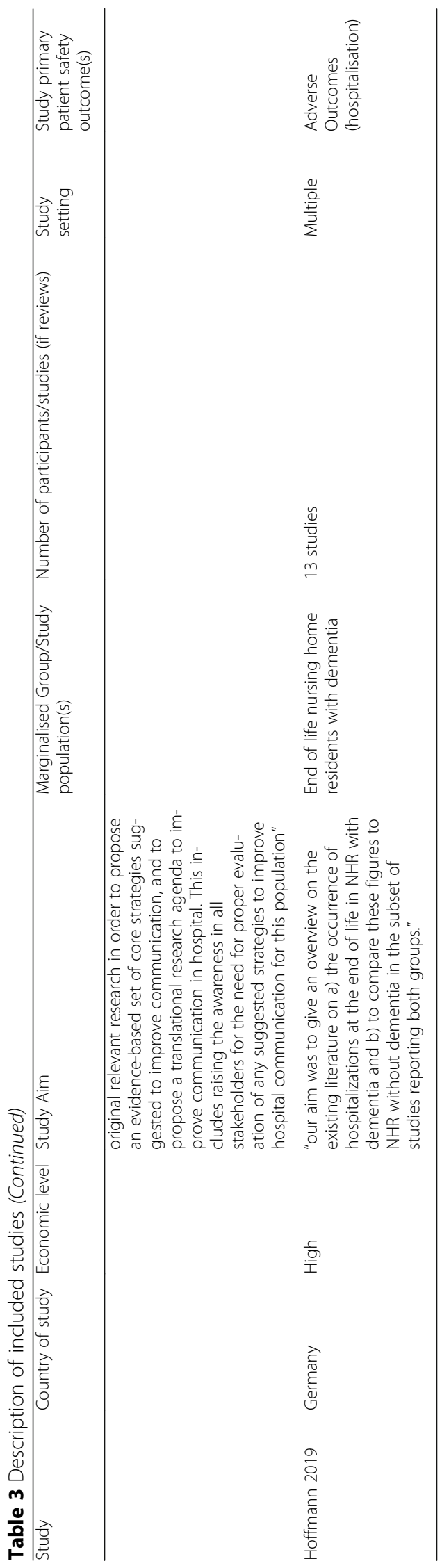


Table 4 Type and frequency of marginalised groups and patient safety issues identified in included studies

\begin{tabular}{|c|c|}
\hline Marginalised Group & Frequency (\%) \\
\hline Ethnic minorities ${ }^{\mathrm{a}}$ & $17(25)$ \\
\hline Frail elderly & $10(15)$ \\
\hline Care home residents & $12(18)$ \\
\hline Low socio-economic status & $7(10)$ \\
\hline Psychiatric patients & $5(7)$ \\
\hline Migrants & $4(6)$ \\
\hline Vulnerable patients & $3(4)$ \\
\hline Visually Impaired & $2(3)$ \\
\hline Intellectually Disabled & $2(3)$ \\
\hline Carers & $1(2)$ \\
\hline Homeless & $1(2)$ \\
\hline Deaf/Hard of Hearing & $2(3)$ \\
\hline Communication Impaired & $1(2)$ \\
\hline Patient Safety Issue ${ }^{b}$ & Frequency (\%) \\
\hline Medication safety issues & $18(26)$ \\
\hline Adverse outcomes & $15(24)$ \\
\hline Near Miss & $7(10)$ \\
\hline Language/communication issues & $6(9)$ \\
\hline Access to care & $5(7)$ \\
\hline Patient safety Incidents/Indicators & $4(6)$ \\
\hline Mortality (including Suicide \& avoidable death) & $6(9)$ \\
\hline Discharge Safety & $2(3)$ \\
\hline Medical Error & $1(2)$ \\
\hline Culturally unsafe healthcare & $1(2)$ \\
\hline diagnostic delay & $1(2)$ \\
\hline Inpatient safety & $1(2)$ \\
\hline
\end{tabular}

${ }^{\text {ancludes aboriginal/indigenous populations }}$

${ }^{\mathrm{b}}$ The denominator is 68 here as one study had two different outcomes (mortality and adverse outcomes)

\section{Team factors $(n=2)$}

Only two examples of this factor were identified, across two separate studies and both concerned team communication.

\section{Discussion}

This scoping review brings together the published academic literature regarding patient safety in marginalised groups and included 67 studies in total. Most studies were from high-income countries and were quantitative (observational) in nature, designed to ascertain whether or not there was a discernible impact on patient safety as a result of the marginalised groups characteristics(s) investigated. Results revealed that in most cases, multiple contributing factors and factor types linked to marginalisation, appeared to lead to negative implications for patient safety. Medication related safety issues and studies around ethnicity constituted the two largest areas with existing evidence. This coalescence however also leaves many gaps in knowledge in the literature allowing for new research agendas to be clearly identified. What is clear, is that there is a relative paucity of patient safety research conducted with respect to marginalised groups in general and that this aligns with a recent priority setting exercise that highlighted vulnerable patients as the top research priority for patient safety research in primary care [96].

Common to studies showing a negative impact on patient safety, was the finding that the studied attributes from the particular marginalised group of interest and their interaction with the health system, created spaces or 'safety vulnerabilities' for patient safety issues to occur (or to be more likely to occur). In mapping the studies reviewed to categories according to the London Protocol Framework, the results of this review point to patient factors being the primary area as to where these vulnerabilities occur. However, many of these patient factors are not transmutable and are necessarily tied to social and organisational context [97], therefore an attempts to improve patient safety for people from marginalised groups requires the system and those working within it to respond and change appropriately. On the basis of the current evidence identified in this review systems, organisations, and those working within it, were for the most part seemingly unable to compensate for or respond adequately to these patient factors and our review highlights that the reasons for this (e.g. work-environmental factors, team factors) have not been well studied.

Access to high quality, safe health care is a fundamental indicator societal and health equity. The findings of this review highlight the need for high quality research to understand the patient, health provider and systemic factors which explain the present inability of health care organisations to provide high and equitable standards of care and safety to marginalised patients. Given that most incident reporting systems are limited in scope [98], explicitly listing marginalised patient groups at high risk for patient safety incidents requires immediate attention by policymakers and practitioners.

An important research implication is the need to acquire a deeper understanding of the underlying vulnerabilities of patient safety in marginalised groups of patients and design improvement strategies. Such understanding and improvements will require researchers to study and address the multi-factorial nature of patient safety issues and their occurrences drawing from a range of disciplines in order to address the multiple factors and issues identified ranging from the micro-level patient-provider interaction to specific and innovative service design to address macro-level issues such as the reduced access to care experienced by people from 


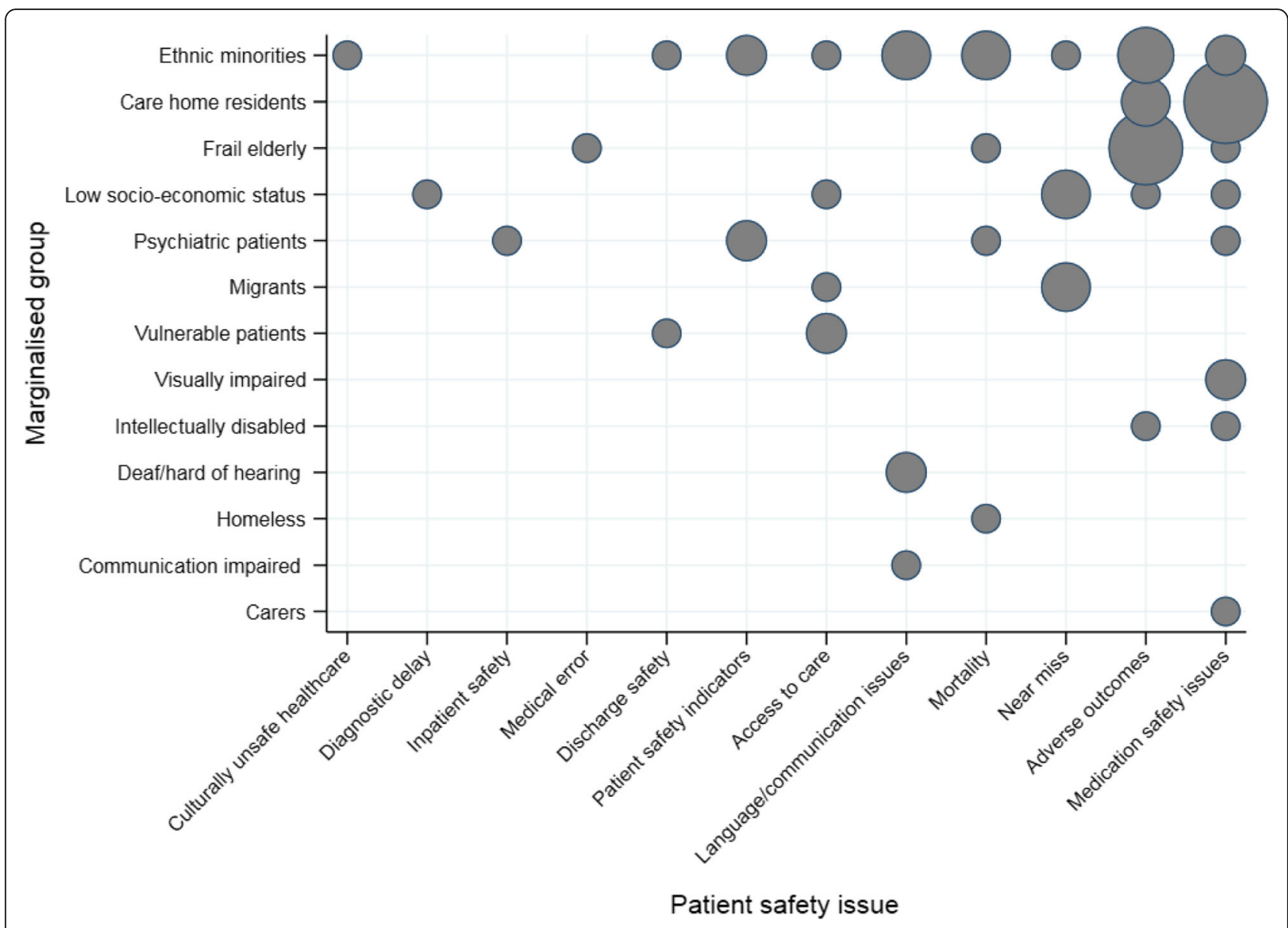

Fig. 2 Bubble plot of the distribution of identified patient safety issues and marginalised groups in included studies

marginalised groups. A number of possible avenues could be productive. Firstly, existing theoretical frameworks can support a critical consideration of the relationships between patient factors, clinical interactions and wider organisational context of systems within patient safety research. For example, the social model of disability makes an important distinction between bodily impairment and disability and associated disadvantage created by environmental and social exclusion [99]. Secondly,the distinction between medical and social models also resonates with previous qualitative research on patient safety highlighting the tendency of patients to highlight the importance of psychosocial aspects of safety such as trust, communication and continuity [100]. Such issues are likely to be even greater concerns for groups where there is little current evidence, such as those with mental health problems, communication and cognitive impairments, or in specific contexts such as homelessness. In addition, research focusing on such groups entails consideration of intersectionality where multiple social markers (e.g. age, gender, ethnicity, socioeconomic status) may synergistically influence the degree to which people are marginalised, vulnerable, excluded or disadvantaged within care systems [101]. Exploration of these issues (quantitatively and qualitatively) will promote further understanding of the overlaps and distinctions regarding marginalisation and vulnerability, as well as an understanding of amenable contributors to patient safety.

The identification and understanding of amenable factors for patient safety provides a crucial base for generating solutions and draws attention to additional avenue for further research focused on marginalised groups and patient safety: the co-design and evaluation of appropriate interventions to improve the quality and safety of care. Whilst there has been a growing acknowledgement on the need for patient and public involvement and engagement to achieve such improvements there is limited evidence of such work, even in relation to black and minority ethnic groups representing the largest marginalised group focused on in the literature reviewed here $[102,103]$. Furthermore, the drive for increasing digitisation within care services in many high income countries $[104,105]$ can potentially increase any existing 


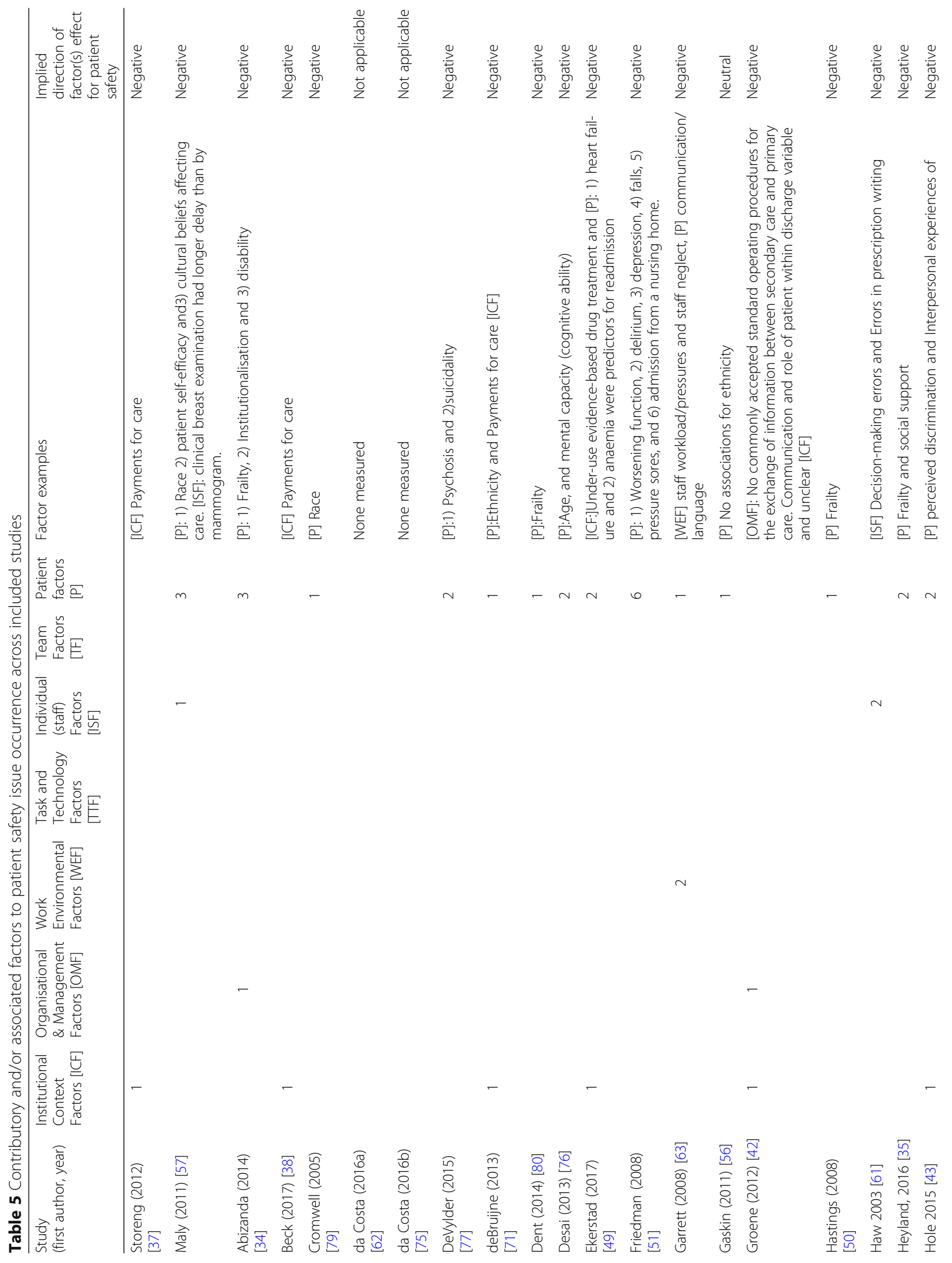




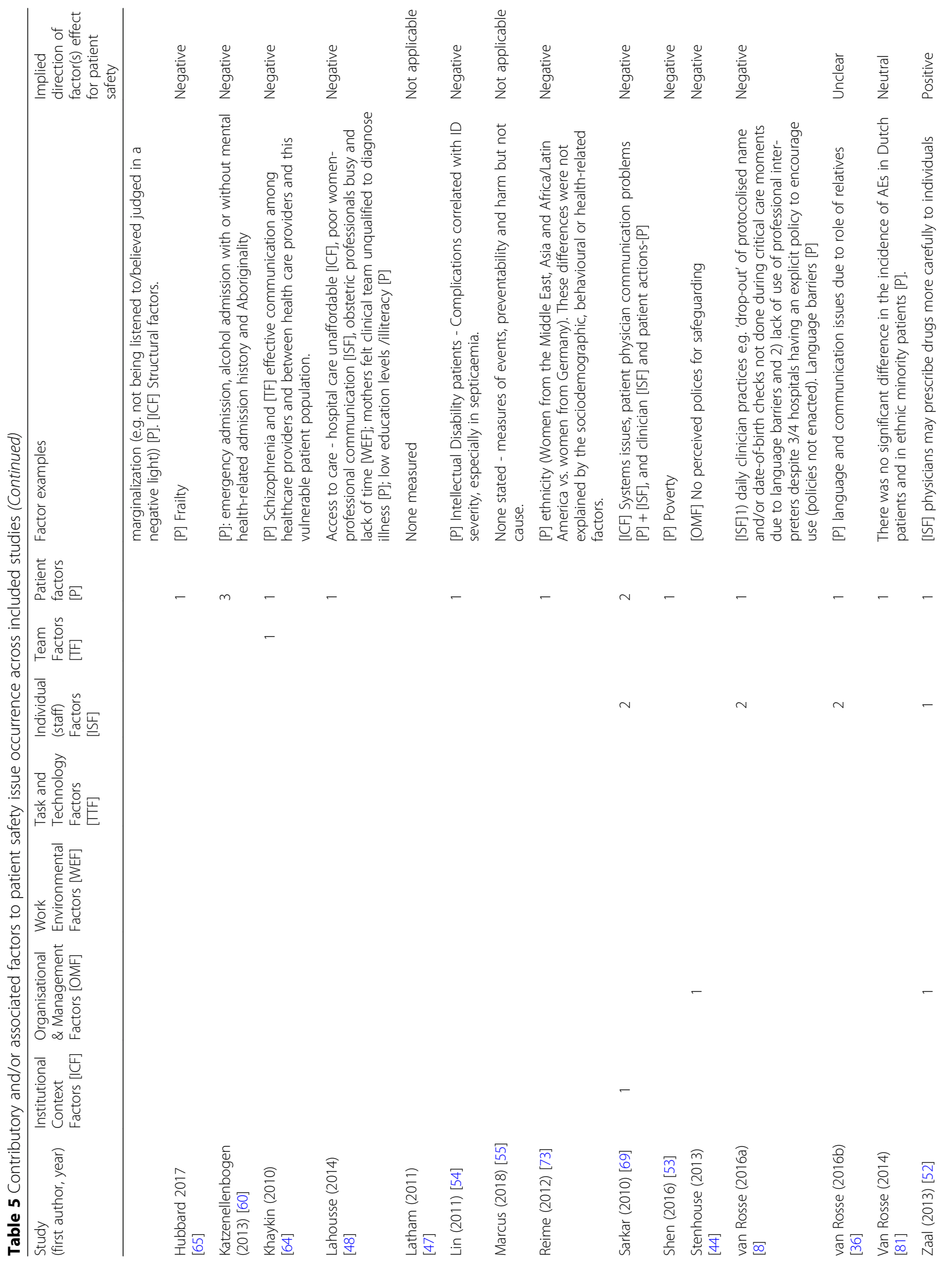




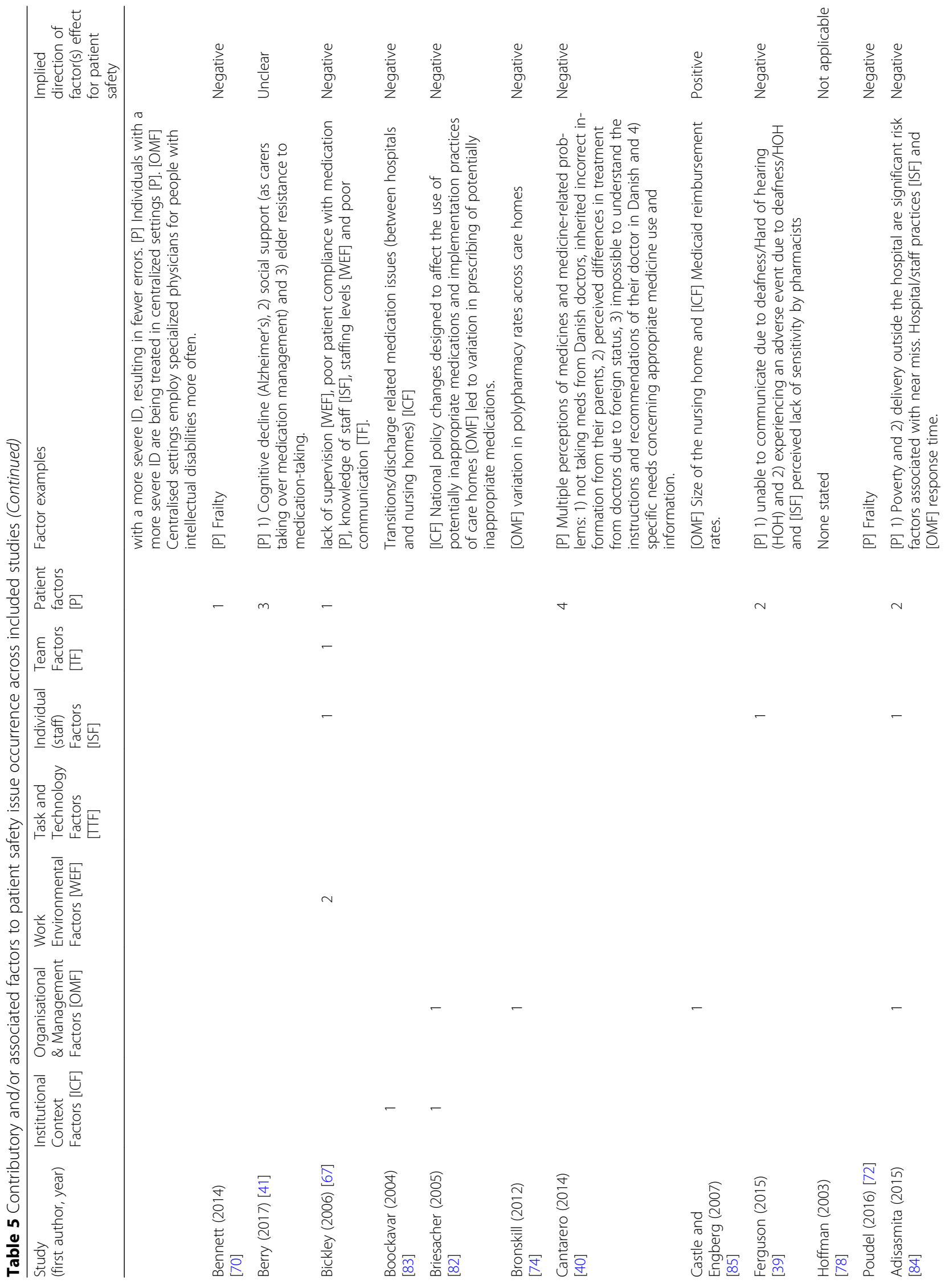




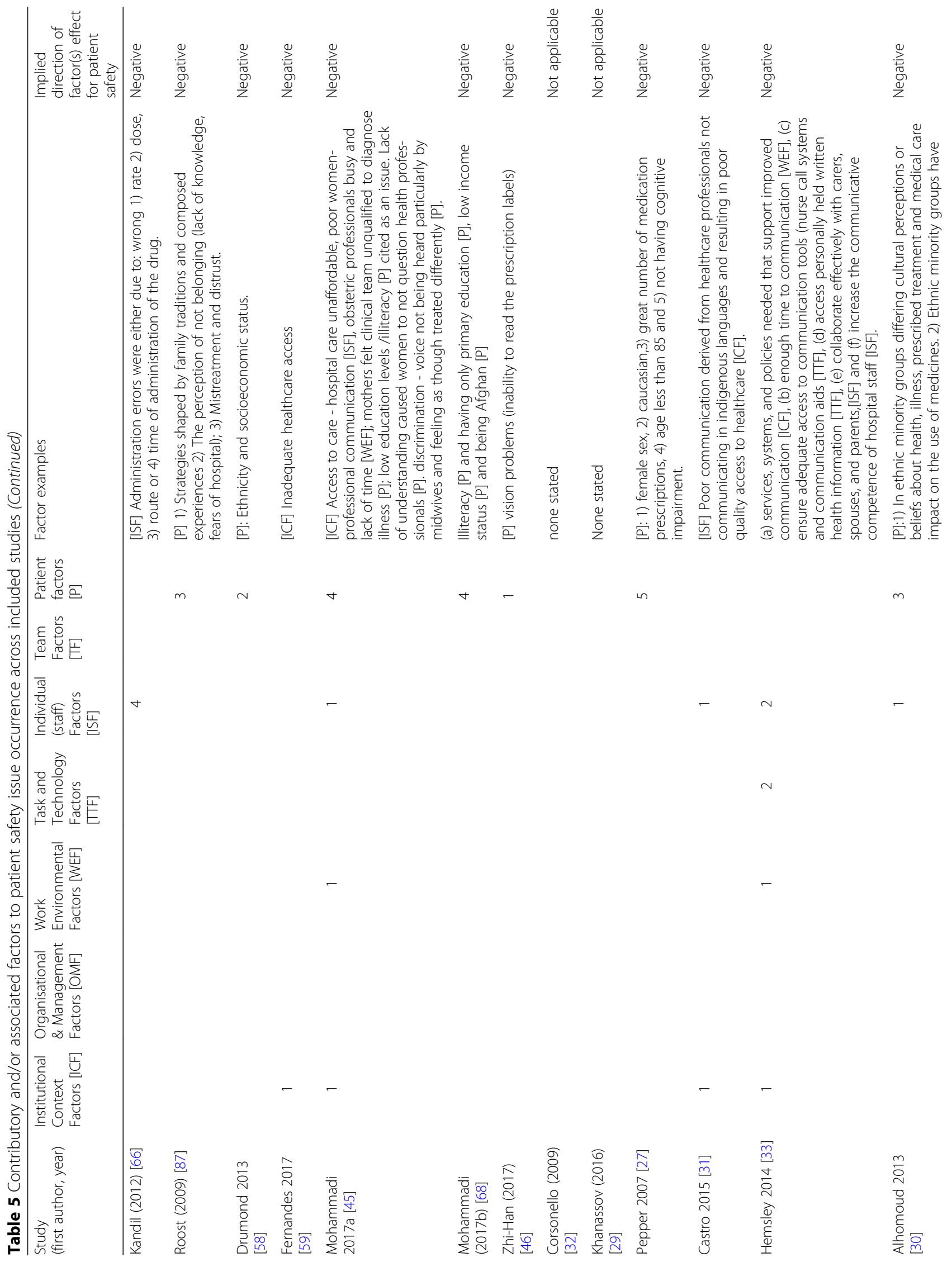




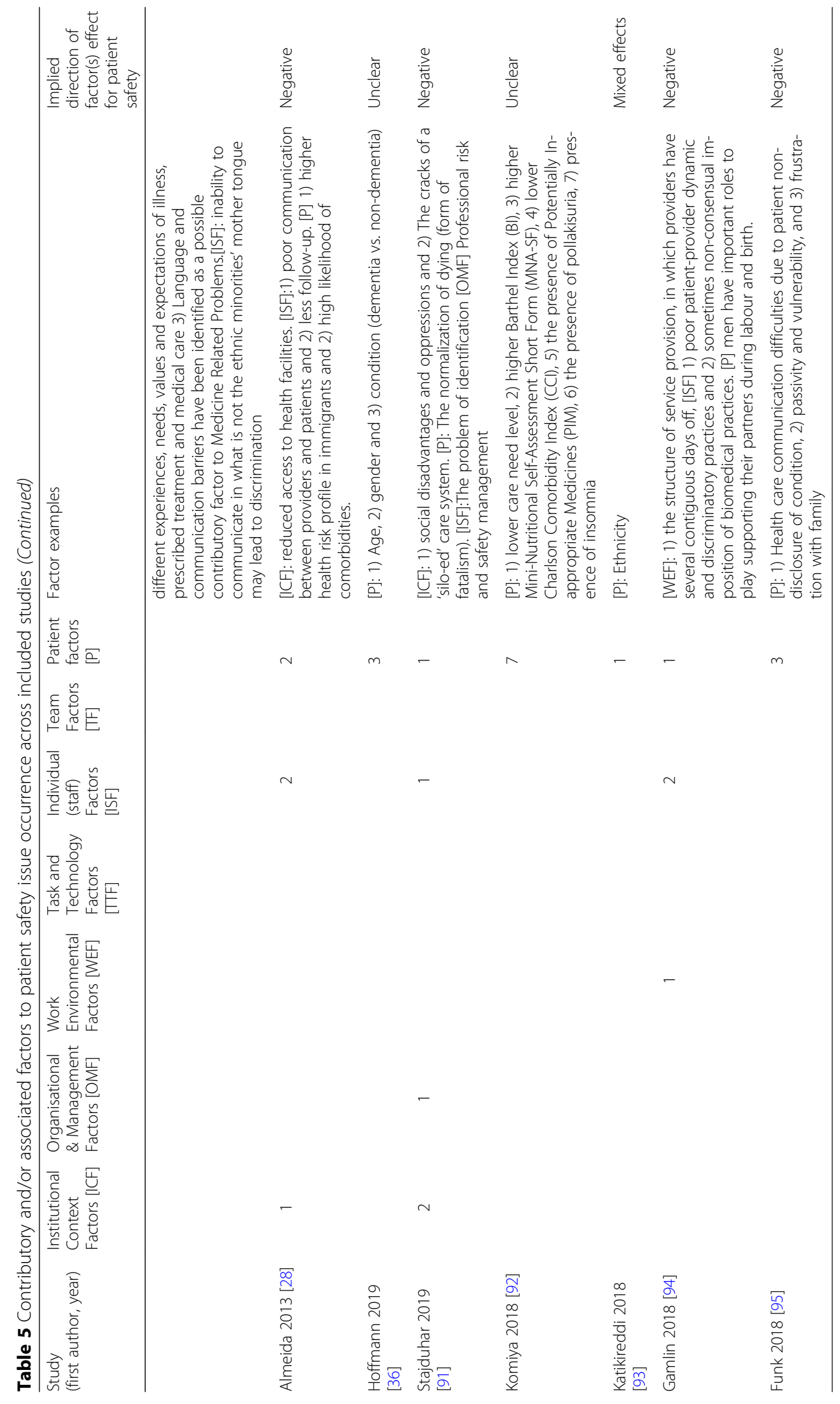


inequalities [106] and indeed create new and as yet unknown patient safety issues for marginalised people(s) [107]. Conversely, there are potentially opportunities for digital technology to reduce inequalities e.g. service gap provision. What is clear however, is that the development of any technology designed to ameliorate patient safety issues for marginalised people(s), will have to first understand the specific issues as a basis for co-design. This entails a focus on multiple dimensions of experience as discussed above; for example physical impairment as well as the material and interactional contexts where technologies are deployed [108].

New research to improve knowledge and understanding of patient safety risks for marginalised groups would also allow policymakers access to information as to where patient safety vulnerabilities are occurring and enable more effective planning and system responsiveness as well as evidence-based policies of inclusion, particularly those that recognize inequities in resources [109]. What is clear from this review, is that the field of patient safety research for marginalised groups has much scope for research, with many areas of patient safety and groups being under-researched.

\section{Strengths and limitations}

This is the first attempt to identify and analyse the academic literature for patient safety within marginalised groups. The study provides a clear platform for further research by highlighting where the gaps in literature are. We conducted systematic searches and double screened all studies. Identifying studies and key words for marginalised groups however was challenging. Thus, there is a possibility that some relevant studies were not included despite thorough attempts to do so. In addition, our focus on studies of marginalised groups meant that we excluded studies where health professionals were the focus and their views may have been different to those of the patients within marginalised groups. Only including studies in the English Language will have also affected the range of possible included studies and consequently meant that majority of studies were from high income countries. Furthermore, defining marginalisation is difficult and often overlaps with other concepts such as vulnerability. We have tried to be inclusive and used search terms from prior published reviews (and appropriate inclusion and exclusion criteria) and we established interrater agreement whilst determining the eligibility of the studies but admittedly operationalising marginalisation involves some degree of subjectivity. Finally, although we found that in the majority of cases, the features of marginalisation in the included studies appeared to lead to negative implications for patient safety for marginalised groups, we cannot say what the strength of this relationship is as scoping reviews do not aim to produce a critically appraised and synthesised result.

\section{Conclusions}

Our review identified a range of patient safety issues for people in marginalised groups, whether these groups are defined by social, economic, demographic or by other means of stratification. The findings indicate the need for further research to understand the intersectional nature of marginalisation and the multi-dimensional nature of patient safety issues, for groups that have been underresearched, including those with mental health problems, communication and cognitive impairments. Understanding which groups in particular are most likely to experience safety issues, what these issues are and why they occur in turn provides a basis for working collaboratively to co-design training, services and/or interventions designed to remove or at the very least minimise these increased risks.

\section{Supplementary information}

Supplementary information accompanies this paper at https://doi.org/10. 1186/s12939-019-1103-2.

Additional file 1. Search Strategy

\section{Abbreviations}

NHS: National health service; OECD: Organisation for economic co-operation and development; PPI: Patient and public involvement

\section{Acknowledgements}

We wish to thank our patient research partners for their involvement in the manuscript.

\section{Authors' contributions}

SCS, MP, CS, SK, SG conceived the basic idea for the research. SCS, CS, SK and MP created the search strategy and MP conducted the searches. Screening was conducted by SCS, GDW, MP, SG, LR, AP. SCS summarised and created the presentation of all data and drafted the manuscript for publication. All authors read, commented on and approved the final manuscript.

\section{Funding}

This work was funded by the National Institute for Health Research (NIHR) Greater Manchester Patient Safety Translational Research Centre (NIHR Greater Manchester PSTRC). The views expressed are those of the author(s) and not necessarily those of the NHS, the NIHR or the Department of Health and Social Care. MP is co-investigator in the Evidence Synthesis Working Group (project 390), which is supported by the NIHR School for Primary Care Research.

\section{Availability of data and materials}

All data generated or analysed during this study are included in this published article [and its supplementary information files].

Ethics approval and consent to participate

Not applicable as the study was a literature review.

Consent for publication

Not applicable.

Competing interests

None. 


\section{Author details}

NIHR Greater Manchester Patient Safety Translational Research Centre, The University of Manchester, Williamson Building, Oxford Rd, Manchester M13 9PL, England. ${ }^{2}$ Centre for Primary Care, The University of Manchester, Williamson Building, Oxford Rd, Manchester M13 9PL, England. ${ }^{3}$ Keele University, Citylabs, Nelson St, Manchester M13 9NQ, England. ${ }^{4} \mathrm{NIHR}$ School for Primary Care Research, Citylabs, Nelson St, Manchester M13 9NQ, England. ${ }^{5}$ Health Innvoation Manchester, Citylabs, Nelson St, Manchester M13 $9 \mathrm{NQ}$, England.

\section{Received: 16 May 2019 Accepted: 27 November 2019}

\section{Published online: 12 February 2020}

\section{References}

1. IOM. In: Kohn LT, Corrigan JM, Donaldson MS, editors. To Err is Human: Building a Safer Health System. Washington DC: National Academy of Sciences; 2000

2. McLeish J. Mothers in EXILE: Maternity experiences of asylum seekers in England; 2002.

3. Shulman C, Hudson BF, Low J, Hewett N, Daley J, Kennedy P, et al. End-oflife care for homeless people: a qualitative analysis exploring the challenges to access and provision of palliative care. Palliat Med. 2018;32(1):36-45.

4. Lecko C. Patient safety and nutrition and hydration in the elderly. UK: The Health Foundation; 2013;1-23

5. Schiffer KSE. Marginalisation, social inclusion and health. Amsterdam: Found Regenboog AMOC Correlation Netw. 2008.

6. Aldridge RW, Story A, Hwang SW, Nordentoft M, Luchenski SA, Hartwell G, et al. Morbidity and mortality in homeless individuals, prisoners, sex workers, and individuals with substance use disorders in high-income countries: a systematic review and meta-analysis. Lancet. 2018;391:241-50.

7. Siddiqui FR. Annotated bibliography on participatory consultations to help aid the inclusion of marginalized perspectives in setting policy agendas. Int J Equity Health. 2014;13(1):124

8. van Rosse F, de Bruijne M, Suurmond J, Essink-Bot ML, Wagner C. Language barriers and patient safety risks in hospital care. A mixed methods study. Int J Nurs Stud. 2016;54:45-53.

9. $\mathrm{Xu} \mathrm{X}$, Chen L. Influencing factors of disability among the elderly in China, 2003-2016: application of Bayesian quantile regression. J Med Econ. 2019; 22(6):605-11.

10. Goodman A, Fleming K, Markwick N, Morrison T, Lagimodiere L, Kerr T. "They treated me like crap and I know it was because I was native": the healthcare experiences of aboriginal peoples living in Vancouver's inner city. Soc Sci Med. 2017;178:87-94.

11. Håkanson C, Öhlén J. Illness narratives of people who are homeless, International J Qual Stud Health Well-being. 2016;11(1):32924. https://doi. org/10.3402/qhw.v11.32924.

12. Panesar SS. deSilva D, Carson-Stevens a, Cresswell KM, Salvilla SA, slight SP, et al. how safe is primary care? A systematic review. BMJ quality \&. Saf. 2016; 25(7):544-53.

13. Michel $P$, Brami J, Chanelière M, Kret M, Mosnier A, Dupie I, et al. Patient safety incidents are common in primary care: a national prospective active incident reporting survey. PLoS One. 2017;12(2):e0165455.

14. Arksey H, O'Malley L. Scoping studies: towards a methodological framework. Int J Soc Res Methodol. 2005;8(1):19-32.

15. GN T-Wl, Goulding L, et al. Identifying the factors affecting the implementation of strategies to promote a safer environment for patients with learning disabilities in NHS hospitals: a mixed-methods study. Health Serv Deliv Res, No 113. Southampton (UK): NIHR J Libr. 2013.

16. Peters MD, Godfrey CM, Khalil H, Mclnerney P, Parker D, Soares CB. Guidance for conducting systematic scoping reviews. Int J Evid-Based Healthc. 2015;13(3):141-6.

17. Health Do. Addressing inequalities - reaching the hard-to-reach groups; 2002. https://webarchive.nationalarchives.gov.uk/20120504011517/ http:// www.dh.gov.uk/prod_consum_dh/groups/dh_digitalassets/@dh/@en/ documents/digitalasset/dh_4065397.pdf.

18. IRISS. Effectively engaging and involving seldom-heard groups. 2011. https://www.iriss.org.uk/resources/insights/effectively-engaging-involvingseldom-heard-groups.

19. Wilde B. 'Seldom heard' report - involving and consulting hard to reach equalities patient groups North Bristol NHS Trust; 2010. http://www.lgbttraining.org.uk/resources/Report.pdf.
20. Little M, Paul K, Jordens CFC, Sayers E-J. Vulnerability in the narratives of patients and their Carers: studies of colorectal Cancer. Health. 2000;4(4):495-510.

21. Hurst SA. Vulnerability in research and health care; describing the elephant in the room? Bioeth. 2008:22(4):191-202.

22. OECD. Integrating social Services for Vulnerable Groups: Bridgng sectors for better service delivery. Paris: OECD Publishing; 2015.

23. Stelfox HT, Palmisani S, Scurlock C, Orav EJ, Bates DW. The "to err is human" report and the patient safety literature. Qual Saf Health Care. 2006;15(3):174-8.

24. Panagioti M, Stokes J, Esmail A, Coventry P, Cheraghi-Sohi S, Alam R, et al. Multimorbidity and patient safety incidents in primary care: a systematic review and meta-analysis. PLoS One. 2015;10(8):e0135947.

25. Huxley CJ, Atherton H, Watkins JA, Griffiths F. Digital communication between clinician and patient and the impact on marginalised groups: a realist review in general practice. Br J Gen Pract. 2015;65(641):e813-21.

26. Innovation $\mathrm{VH}$. Covidence systematic review software. Melbourne, Australia.

27. Levac D, Colquhoun H, O'Brien KK. Scoping studies: advancing the methodology. Implementation science : IS. 2010;5:69-

28. T-ASV C. Systems analysis of clinical incidents: the London protocol. Clinical Risk. 2004;10(6):211-20.

29. Pepper GAT, G. L. Medication errors in nursing homes: incidence and reduction strategies. J Pharm Finance, Econ Policy. 2008;16(1):5-133.

30. Almeida LM, Caldas J, Ayres-de-Campos D, Salcedo-Barrientos D, Dias S. Maternal healthcare in migrants: a systematic review. Matern Child Health J. 2013;17(8):1346-54.

31. Khanassov V, Pluye P, Descoteaux S, Haggerty JL, Russell G, Gunn J, et al. Organizational interventions improving access to community-based primary health care for vulnerable populations: a scoping review. Int J Equity Health. 2016;15(1):168.

32. Alhomoud F, Dhillon S, Aslanpour Z, Smith F. Medicine use and medicinerelated problems experienced by ethnic minority patients in the United Kingdom: a review. Int J Pharm Pract. 2013;21(5):277-87.

33. Castro A, Savage V, Kaufman $\mathrm{H}$. Assessing equitable care for indigenous and Afrodescendant women in Latin America. Revista panamericana de salud publica $=$. Pan Am J Public Health. 2015;38(2):96-109.

34. Corsonello A, Pranno L, Garasto S, Fabietti P, Bustacchini S, Lattanzio F. Potentially inappropriate medication in elderly hospitalized patients. Drugs Aging. 2009;26(Suppl 1):31-9.

35. Hemsley B, Balandin S. A metasynthesis of patient-provider communication in hospital for patients with severe communication disabilities: informing new translational research. Augment Altern Commun (Baltimore, Md : 1985). 2014;30(4):329-43.

36. Hoffmann F, Strautmann A, Allers K. Hospitalization at the end of life among nursing home residents with dementia: a systematic review. BMC Palliat Care. 2019;18(1):77.

37. Abizanda P, Romero L, Sanchez-Jurado PM, Martinez-Reig M, AlfonsoSilguero SA, Rodriguez-Manas L. Age, frailty, disability, institutionalization, multimorbidity or comorbidity. Which are the main targets in older adults? J Nutr Health Aging. 2014;18(6):622-7.

38. Heyland DK, Ilan R, Jiang $X$, You JJ, Dodek P. The prevalence of medical error related to end-of-life communication in Canadian hospitals: results of a multicentre observational study. BMJ Qual Saf. 2016;25(9):671-9.

39. van Rosse F, Suurmond J, Wagner C, de Bruijne M, Essink-Bot M-L. Role of relatives of ethnic minority patients in patient safety in hospital care: a qualitative study. BMJ Open. 2016;6(4):e009052.

40. Storeng KT, Drabo S, Filippi V. Too poor to live? A case study of vulnerability and maternal mortality in Burkina Faso. Glob Health Promot. 2013;20(1 Suppl):33-8.

41. Beck AF, Solan LG, Brunswick SA, Sauers-Ford H, Simmons JM, Shah S, et al. Socioeconomic status influences the toll paediatric hospitalisations take on families: a qualitative study. BMJ Qual Saf. 2017;26(4):304-11.

42. Ferguson M, Liu M. Communication needs of patients with altered hearing ability: informing pharmacists' patient care services through focus groups. J Am Pharm Assoc : JAPhA. 2015;55(2):153-60.

43. Cantarero-Arevalo L, Kassem D, Traulsen JM. A culturally competent education program to increase understanding about medicines among ethnic minorities. Int J Clin Pharm. 2014;36(5):922-32.

44. Berry B, Apesoa-Varano EC. Medication takeovers: Covert druggings and behavioral control in Alzheimer's. Soc Sci Med (1982). 2017;188:51-9.

45. Groene RO, Orrego C, Sunol R, Barach P, Groene O. "It's like two worlds apart": an analysis of vulnerable patient handover practices at discharge from hospital. BMJ Qual Saf. 2012;21(Suppl 1):i67-75. 
46. Hole RD, Evans M, Berg LD, Bottorff JL, Dingwall C, Alexis C, et al. Visibility and voice: aboriginal people experience culturally safe and unsafe health care. Qual Health Res. 2015;25(12):1662-74.

47. Stenhouse RC. Safe enough in here?': patients' expectations and experiences of feeling safe in an acute psychiatric inpatient ward. J Clin Nurs. 2013;22(21-22):3109-19.

48. Mohammadi S, Carlbom A, Taheripanah R, Essen B. Experiences of inequitable care among afghan mothers surviving near-miss morbidity in Tehran, Iran: a qualitative interview study. Int J Equity Health. 2017;16(1):121.

49. Zhi-Han L, Hui-Yin Y, Makmor-Bakry M. Medication-handling challenges among visually impaired population. Arch Pharm Pract. 2017;8(1):8-14.

50. Latham K, Waller S, Schaitel J. Do best practice guidelines improve the legibility of pharmacy labels for the visually impaired? Ophthalmic Physiol Opt : J Br Coll Ophthalmic Opticians (Optometrists). 2011;31(3):275-82.

51. Lahousse L, Maes B, Ziere G, Loth DW, Verlinden VJ, Zillikens MC, et al. Adverse outcomes of frailty in the elderly: the Rotterdam study. Eur J Epidemiol. 2014;29(6):419-27.

52. Ekerstad N, Bylin K, Karlson BW. Early rehospitalizations of frail elderly patients - the role of medications: a clinical, prospective, observational trial. Drug, healthcare and patient safety. 2017;9:77-88.

53. Hastings SN, Purser JL, Johnson KS, Sloane RJ, Whitson HE. Frailty predicts some but not all adverse outcomes in older adults discharged from the emergency department. J Am Geriatr Soc. 2008;56(9):1651-7.

54. Friedman SM, Mendelson DA, Bingham KW, McCann RM. Hazards of hospitalization: residence prior to admission predicts outcomes. The Gerontologist. 2008;48(4):537-41.

55. Zaal RJ, van der Kaaij AD, Evenhuis HM, van den Bemt PM. Prescription errors in older individuals with an intellectual disability: prevalence and risk factors in the healthy ageing and intellectual disability study. Res Dev Disabil. 2013;34(5):1656-62.

56. Shen JJ, Cochran CR, Mazurenko O, Moseley CB, Shan G, Mukalian R, et al. Racial and insurance status disparities in patient safety indicators among hospitalized patients. Ethn Dis. 2016;26(3):443-52.

57. Lin JA, Liao CC, Chang CC, Chang H, Chen TL. Postoperative adverse outcomes in intellectually disabled surgical patients: a nationwide population-based study. PLoS One. 2011;6(10):e26977.

58. Marcus SC, Hermann RC, Frankel MR, Cullen SW. Safety of Psychiatric Inpatients at the Veterans Health Administration. Psychiatr Serv (Washington, DC). 2018;69(2):204-10.

59. Gaskin DJ, Spencer CS, Richard P, Anderson G, Powe NR, LaVeist TA. Do minority patients use lower quality hospitals? Inq : J Med Care Orga, Provision Financ. 2011;48(3):209-20.

60. Maly RC, Leake B, Mojica CM, Liu Y, Diamant AL, Thind A. What influences diagnostic delay in low-income women with breast cancer? J Women's Health (2002). 2011;20(7):1017-23.

61. Drumond E, Abreu DM, Machado C, Gomes F, Franca E. Racial disparities and avoidable infant mortality in a city of southeastern Brazil, 2001-09. J Trop Pediatr. 2013;59(1):23-8

62. Fernandes KG, Souza RT, Leal MC, Moura EC, Santos LM, Cecatti JG. Ethnic differences in maternal near miss. Arch Gynecol Obstet. 2017;296(6):1063-70.

63. Katzenellenbogen JM, Sanfilippo FM, Hobbs MS, Knuiman MW, Bessarab D, Durey $A$, et al. Voting with their feet--predictors of discharge against medical advice in aboriginal and non-aboriginal ischaemic heart disease inpatients in Western Australia: an analytic study using data linkage. BMC Health Serv Res. 2013:13:330.

64. Haw C, Stubbs J. Prescribing errors at a psychiatric hospital. Pharm Pract. 2003;10:64-6.

65. da Costa FA, Silvestre L, Periquito C, Carneiro C, Oliveira P, Fernandes Al, et al. Drug-related problems identified in a sample of Portuguese institutionalised elderly patients and Pharmacists' interventions to improve safety and effectiveness of medicines. Drugs - Real World Outcomes. 2016:3(1):89-97.

66. Garrett PW, Dickson HG, Young L, Whelan AK. "The happy migrant effect": perceptions of negative experiences of healthcare by patients with little or no English: a qualitative study across seven language groups. Qual Saf Health Care. 2008;17(2):101-3

67. Khaykin E, Ford DE, Pronovost PJ, Dixon L, Daumit GL. National estimates of adverse events during nonpsychiatric hospitalizations for persons with schizophrenia. Gen Hosp Psychiatry. 2010;32(4):419-25.

68. Hubbard RE, Peel NM, Samanta M, Gray LC, Mitnitski A, Rockwood K. Frailty status at admission to hospital predicts multiple adverse outcomes. Age Ageing. 2017;46(5):801-6.
69. Kandil M, Sayyed T, Emarh M, Ellakwa H, Masood A. Medication errors in the obstetrics emergency ward in a low resource setting. J Maternal-fetal Neonatal Med : Official J Eur Assoc Perinat Med,Fed Asia Oceania Perinat Soc, Int Soc Perinat Obstet. 2012;25(8):1379-82.

70. Bickley H, Kapur N, Hunt IM, Robinson J, Meehan J, Parsons R, et al. Suicide in the homeless within 12 months of contact with mental health services : a national clinical survey in the UK. Soc Psychiatry Psychiatr Epidemiol. 2006;41(9):686-91.

71. Mohammadi S, Saleh Gargari S, Fallahian M, Kallestal C, Ziaei S, Essen B. Afghan migrants face more suboptimal care than natives: a maternal nearmiss audit study at university hospitals in Tehran, Iran. BMC Pregnancy Childbirth. 2017;17(1):64

72. Sarkar U, Handley MA, Gupta R, Tang A, Murphy E, Seligman HK, et al. What happens between visits? Adverse and potential adverse events among a low-income, urban, ambulatory population with diabetes. Qual Saf Health Care. 2010;19(3):223-8

73. Bennett A, Gnjidic D, Gillett M, Carroll P, Matthews S, Johnell K, et al. Prevalence and impact of fall-risk-increasing drugs, polypharmacy, and drug-drug interactions in robust versus frail hospitalised falls patients: a prospective cohort study. Drugs Aging. 2014;31(3):225-32.

74. de Bruijne MC, van Rosse F, Uiters E, Droomers M, Suurmond J, Stronks K, et al. Ethnic variations in unplanned readmissions and excess length of hospital stay: a nationwide record-linked cohort study. Eur J Pub Health. 2013;23(6):964-71.

75. Poudel A, Peel NM, Nissen LM, Mitchell CA, Gray LC, Hubbard RE. Adverse Outcomes in Relation to Polypharmacy in Robust and Frail Older Hospital Patients. J Am Med Dir Assoc. 2016;17(8):767-e9-.e13.

76. Reime B, Janssen PA, Farris L, Borde T, Hellmers C, Myezwa H, et al. Maternal near-miss among women with a migrant background in Germany. Acta Obstet Gynecol Scand. 2012;91(7):824-9.

77. Bronskill SE, Gill SS, Paterson JM, Bell CM, Anderson GM, Rochon PA. Exploring variation in rates of polypharmacy across long term care homes. J Am Med Dir Assoc. 2012;13(3):309.e15-21.

78. da Costa FA, Periquito C, Carneiro MC, Oliveira P, Fernandes Al, Cavaco-Silva $P$. Potentially inappropriate medications in a sample of Portuguese nursing home residents: does the choice of screening tools matter? Int J Clin Pharm. 2016;38(5):1103-11

79. Desai RJ, Williams CE, Greene SB, Pierson S, Hansen RA. Anticoagulant medication errors in nursing homes: characteristics, causes, outcomes, and association with patient harm. J Healthc Risk Manag : J Am Soc Healthc Risk Manag. 2013;33(1):33-43.

80. DeVylder JE, Lukens EP, Link BG, Lieberman JA. Suicidal ideation and suicide attempts among adults with psychotic experiences: data from the collaborative psychiatric epidemiology surveys. JAMA psychiatry. 2015;72(3):219-25.

81. Hoffman SB, Powell-Cope G, MacClellan L, Bero K. BedSAFE. A bed safety project for frail older adults. J Gerontol Nurs. 2003;29(11):34-42.

82. Cromwell J, McCall NT, Burton J, Urato C. Race/ethnic disparities in utilization of lifesaving technologies by Medicare ischemic heart disease beneficiaries. Med Care. 2005:43(4):330-7.

83. Dent E, Hoogendijk EO. Psychosocial factors modify the association of frailty with adverse outcomes: a prospective study of hospitalised older people. BMC Geriatr. 2014;14:108.

84. van Rosse F, Essink-Bot M-L, Stronks K, de Bruijne M, Wagner C. Ethnic minority patients not at increased risk of adverse events during hospitalisation in urban hospitals in the Netherlands: results of a prospective observational study. BMJ Open. 2014;4(12):e005527.

85. Briesacher B, Limcangco R, Simoni-Wastila L, Doshi J, Gurwitz J. Evaluation of nationally mandated drug use reviews to improve patient safety in nursing homes: a natural experiment. J Am Geriatr Soc. 2005;53(6):991-6.

86. Boockvar K, Fishman E, Kyriacou CK, Monias A, Gavi S, Cortes T. Adverse events due to discontinuations in drug use and dose changes in patients transferred between acute and long-term care facilities. Arch Intern Med. 2004;164(5):545-50.

87. Adisasmita A, Smith CV, El-Mohandes AA, Deviany PE, Ryon JJ, Kiely M, et al. Maternal characteristics and clinical diagnoses influence obstetrical outcomes in Indonesia. Matern Child Health J. 2015;19(7):1624-33.

88. Castle NG, Wagner LM, Ferguson JC, Handler SM. Nursing home deficiency citations for safety. J Aging Soc Policy. 2011;23(1):34-57.

89. Flores G, Ngui E. Racial/ethnic disparities and patient safety. Pediatr Clin N Am. 2006;53(6):1197-215.

90. Rööst M, Jonsson C, Liljestrand J, Essén B. Social differentiation and embodied dispositions: a qualitative study of maternal care-seeking behaviour for near-miss morbidity in Bolivia. Reprod Health. 2009;6(1):13. 
91. Stajduhar Kl, Mollison A, Giesbrecht M, McNeil R, Pauly B, Reimer-Kirkham S, et al. "Just too busy living in the moment and surviving": barriers to accessing health care for structurally vulnerable populations at end-of-life. BMC Palliat Care. 2019;18(1):11.

92. Komiya H, Umegaki H, Asai A, Kanda S, Maeda K, Shimojima T, et al. Factors Associated with Polypharmacy in elderly home-care patients. Geriatr Gerontol Int. 2018;18(1):33-41.

93. Katikireddi SV, Cezard G, Bhopal RS, Williams L, Douglas A, Millard A, et al. Assessment of health care, hospital admissions, and mortality by ethnicity: population-based cohort study of health-system performance in Scotland. Lancet Public Health. 2018;3(5):e226-e36.

94. Gamlin J, Holmes S. Preventable perinatal deaths in indigenous Wixárika communities: an ethnographic study of pregnancy, childbirth and structural violence. BMC Pregnancy Childbirth. 2018;18(1):243.

95. Funk A, Garcia C, Mullen T. CE: original research: understanding the hospital experience of older adults with hearing impairment. Am J Nurs. 2018;118(6): 28-34.

96. Morris RL, Stocks SJ, Alam R, Taylor S, Rolfe C, Glover SW, et al. Identifying primary care patient safety research priorities in the UK: a James Lind Alliance priority setting partnership. BMJ Open. 2018;8(2):e020870.

97. Johnstone $\mathbf{M}-J$, Kanitsaki O. Culture, language, and patient safety: making the link. Int J Qual Health Care. 2006;18(5):383-8.

98. Shojania KG. The frustrating case of incident-reporting systems. Qual Saf Health Care. 2008;17(6):400-2.

99. Haegele JA, Hodge S. Disability discourse: overview and critiques of the medical and social models. Quest. 2016;68(2):193-206.

100. Rhodes P, McDonald R, Campbell S, Daker-White G, Sanders C. Sensemaking and the co-production of safety: a qualitative study of primary medical care patients. Sociol Health IIIn. 2016;38(2):270-85.

101. Thomas C, Milligan C. Dementia, disability rights and disablism: understanding the social position of people living with dementia. Disabil Soc. 2018;33(1):115-31.

102. Ocloo J, Matthews R. From tokenism to empowerment: progressing patient and public involvement in healthcare improvement. BMJ quality \&amp. Saf. 2016;25(8):626-32.

103. Johnstone MJ, Kanitsaki O. Engaging patients as safety partners: some considerations for ensuring a culturally and linguistically appropriate approach. Health policy (Amsterdam, Netherlands). 2009;90(1):1-7.

104. Bhavnani SP, Narula J, Sengupta PP. Mobile technology and the digitization of healthcare. Eur Heart J. 2016;37(18):1428-38.

105. NHS E. Five year forward view 2014

106. Joski PJ, Roblin DW, Allison JJ, Houston TK II, Becker ER. Disparities in use of a personal health record in a managed care organization. J Am Med Inform Assoc. 2009;16(5):683-9.

107. Chang BL, Bakken S, Brown SS, Houston TK, Kreps GL, Kukafka R, et al. Bridging the digital divide: reaching vulnerable populations. J Am Med Inform Assoc: JAMIA. 2004;11(6):448-57.

108. Ong BS. C. Exploring engagement with digital screens for collecting patient feedback in clinical waiting rooms: the role of touch and place. Health. In Press.

109. Lynam MJ, Cowley S. Understanding marginalization as a social determinant of health. Crit Public Health. 2007;17(2):137-49.

\section{Publisher's Note}

Springer Nature remains neutral with regard to jurisdictional claims in published maps and institutional affiliations.

Ready to submit your research? Choose BMC and benefit from:

- fast, convenient online submission

- thorough peer review by experienced researchers in your field

- rapid publication on acceptance

- support for research data, including large and complex data types

- gold Open Access which fosters wider collaboration and increased citations

- maximum visibility for your research: over $100 \mathrm{M}$ website views per year

At BMC, research is always in progress.

Learn more biomedcentral.com/submissions 